\title{
¿ES POSIBLE HABLAR DE COMPLICIDAD EN EL DELITO DE LAVADO DE ACTIVOS?
}

Alfonso Giraldo Saavedra

Universidad Santo Tomas

Facultad de Ciencias Jurídicas y Políticas

Maestría en Derecho Penal

Junio de 2017 
Tabla de contenido

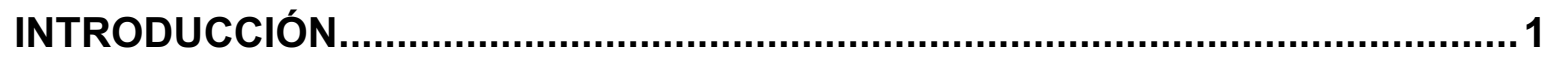

I. CARACTERIZACIÓN DEL LAVADO DE ACTIVOS .....................................

Contexto socio-económico del lavado de activos .......................................

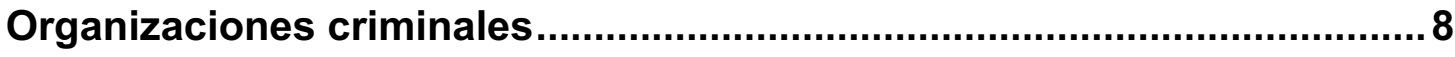

Financiación del terrorismo ...................................................................10

Tecnología e informática en el lavado de activos....................................11

Lavado de activos en instrumentos financieros y comerciales ...............13

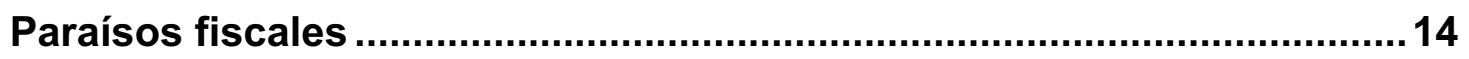

Las remesas en el lavado de activos .......................................................16

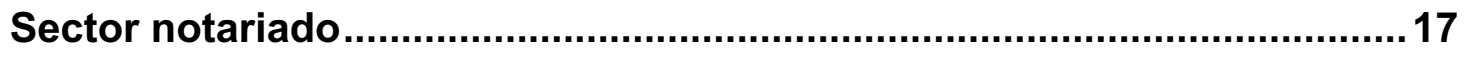

Organización internacional contra el lavado de activos ............................18

II. ELEMENTOS NORMATIVOS DEL LAVADO DE ACTIVOS EN COLOMBIA Y SUPUESTOS PUNIBLES DE LA COMPLICIDAD .............................................23

Normatividad colombiana sobre lavado de activos ...............................24 
Elementos de la figura delictiva del lavado de activos

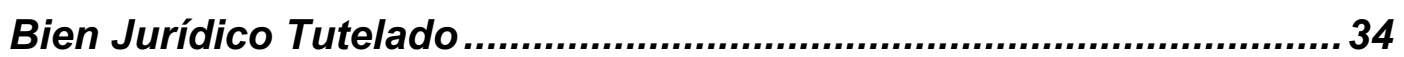

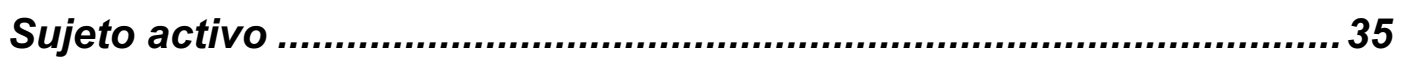

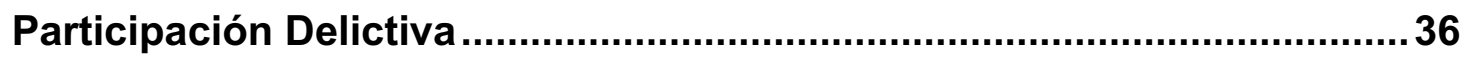

Tipologías de configuración del delito de lavado de activos..............37

III. NORMATIVIDAD INTERNACIONAL EN EL LAVADO DE ACTIVOS...........52

Posible complicidad en el blanqueo de capitales desde el sistema penal

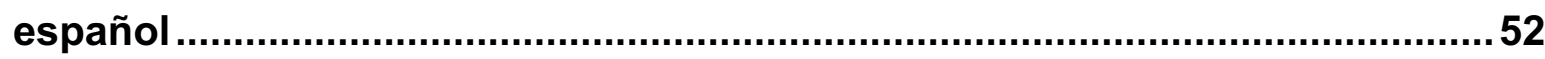

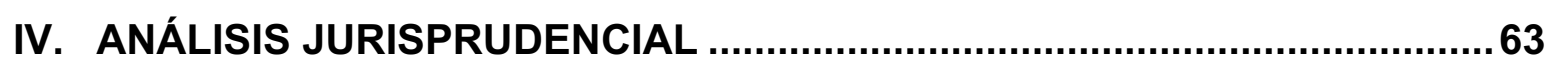

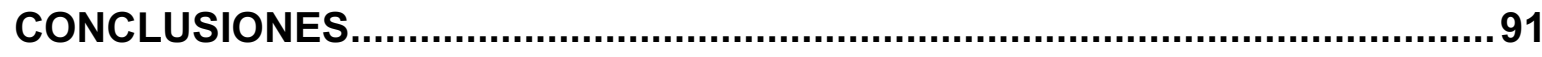

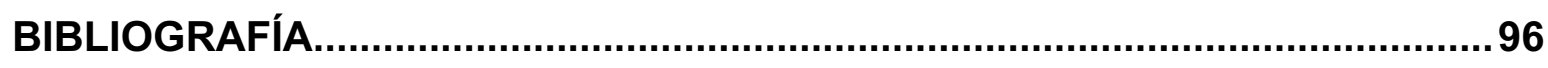




\section{Introducción}

Son diversas y variadas las estrategias que puede usar la delincuencia, con el fin de lograr ingentes ingresos de manera inmediata; esto, lleva a un panorama muy amplio sobre tipologías delictivas, asociadas en su estudio al derecho penal económico. De este campo criminológico, hace parte el delito de lavado de activos que, desde su origen, ha tendido a ser catalogado como delito conexo a otras modalidades delictivas asociadas a grupos trasnacionales de crimen organizado, convertidas en verdaderas mafias que pueden actuar más allá de las fronteras nacionales.

A través del desarrollo del documento, se profundiza en el modus operandi del crimen organizado para el delito en particular antes mencionado, con el fin de caracterizar la manera como la acción delictiva, desemboca en problemas de desempeño económico y trastornos en la convivencia social. En este sentido, la acción criminal asociada al lavado de activos, es el resultado de una serie de acciones ilegales, que dan movimiento a un círculo vicioso que no se queda solamente en el hecho de cómo un dinero, producto de una actividad delictiva, deja de ser ilegal para ser encajado en un mundo de circulación legal de efectivo, con efectos negativos en la economía nacional e internacional, sino, incluso de cómo ese dinero puede ser factor de la comisión de delitos tan graves como los de lesa humanidad. 
Todo lo anterior, sucede con la participación de una amplia cadena humana, que involucra, por una parte, a quienes son autores materiales o determinadores en la comisión delictiva para la generación de capitales a partir de la realización de actividades como: tráfico de drogas, compra y venta de armas, el accionar de actividades terroristas, participación en el tráfico de personas, secuestro, extorsión, entre otros. Lo anterior, en algunos casos con la anuencia de funcionarios públicos, empleados del sistema financiero, como también de personas que, en el piso de la cadena, participan del lavado de activos, actuando contrario a su voluntad, o desconociendo la compleja responsabilidad penal que resulta de mover dineros en productos financieros a su nombre, como también de transportarlos físicamente.

Considerar que existen rangos en la cadena delictiva por la que se logra el lavado de activos, suscita la formulación del problema jurídico que se plantea desarrollar en la actual investigación, a saber, la admisión en la legislación colombiana de la complicidad en el delito de lavado de activos, particularmente para los casos en los que la persona sindicada actúa sin un conocimiento cierto de la procedencia de los recursos, en una conducta que puede estar asociada con situaciones de temor reverencial por los vínculos sociales que tiene con quien la persuade para la realización de la actividad delictiva, que para tal efecto, requiere de una lectura contextual de la configuración socio-jurídica del delito en el marco de las leyes colombianas, proponiendo para ello una revisión rigurosa no sólo de la legislación colombiana y de la jurisprudencia nacional, sino también de la doctrina formulada para este tema preciso, acompañando tal propósito, con un análisis de 
derecho comparado entre la legislación nacional en la materia, y la legislación española.

Se genera así una formulación hipotética, por la que se señala que existen situaciones dentro de la cadena delictiva del lavado de activos, en la que la participación de algunos sujetos activos del delito, se produce siguiendo un temor reverencial por el que el(los) partícipe(s) acuden a la realización de la conducta por el cumplimiento subordinado de órdenes en el contexto, que produce principalmente una relación laboral, o de amenaza. En este orden de ideas, se considera que existen sujetos partícipes, que en la necesidad por ejemplo de mantener su trabajo y recibiendo por ello una pequeña propina, prestan su nombre a sus jefes para la apertura de productos financieros, a los que no les hacen el adecuado seguimiento y control, y estos quedan al arbitrio de quién los persuadió a su apertura. Miles de casos jurídicos, muestran que a través de estos productos posteriormente, se manejan dineros ilícitos, caso similar, al que se presta para que por un tiempo se coloque a su nombre todo tipo de activos, por ello, son los titulares responsables de tales productos financieros y la experiencia enseña que en muchos de estos casos, ignoran el origen y manejo de estos dineros, sin embargo responden a título de autor o coautor en la comisión del delito de lavado de activos.

Es por esto, que se considera clave seguir una ruta metodológica por la que conceptualmente se aborden las tipologías de la comisión de este delito, para luego ser analizadas de manera comparada con la legislación española. De igual manera, se propone hacer un análisis jurisprudencial colombiano, que ponga en evidencia la 
manera como dicha jurisprudencia, de cierta manera no ha agotado el análisis contextual de la comisión del delito, desconociendo como se advertía, unas relaciones sociales de subordinación que ante su no existencia, posiblemente evitarían la comisión del delito, esto, sin perder de vista que los altos tribunales presumen una regla de la experiencia, la cual supone, que si un fenómeno es repetitivo en circunstancias similares, los efectos de las conductas también lo serán.

Se propone para su desarrollo, la elaboración de cuatro partes en el cuerpo del trabajo, dividas por capítulos en el actual documento. Así, para la primera parte del trabajo, ahonda en la caracterización del lavado de activos o blanqueo de capitales, desde la conceptualización misma del delito en el marco de su explicación institucional, exponiendo tanto sus antecedentes, como las variables a contemplar en el contexto socio-económico, que se extrapola en una relación con la política criminal internacional, la cual destaca la importancia en la observancia de elementos tales como las redes trasnacionales y el uso de tecnologías e información. En este mismo capítulo, se recurre a revisar los medios sobre los que se puede dar el lavado de activos, que como se indicaba, pueden obedecer por ejemplo a transacciones virtuales tipo las bursátiles o financieras, como también de bienes reales, caso del narcotráfico, $\mathrm{u}$ otras actividades delictivas.

En el segundo capítulo del trabajo, se propone abordar el tema de la referenciación normativa del delito de lavado de activos, considerando para ello importante dividir esta parte del trabajo en tres segmentos: el primero, que aborda los elementos normativos del lavado de activos, desde las disposiciones nacionales, 
luego, abarcando detalladamente la figura delictiva desde su descripción normativa, para finalmente, generar una aproximación a la participación delictiva desde el tipo que se propone para el documento que es el de la complicidad.

El tercer capítulo del documento, aborda la legislación internacional en la materia, enfocado principalmente en lo que tiene que ver con la legislación española, por ser el país más cercano a nuestra perspectiva latinoamericana; esto considerando la herencia ibérica que se tiene en la institucionalidad nacional y por ello se presta especial atención a la revisión de tipos penales que pueden ser consecuentes con la complicidad en delitos económicos, en especial con la conducta que se revisa para este documento que es la configuración del lavado de activos.

Finalmente, en el cuarto capítulo se pretende realizar un análisis jurisprudencial que revisa casos que han sido analizados por la Corte Suprema de Justicia en su Sala Penal, y que, en su tratamiento argumentativo y riguroso, permiten profundizar en el contraste con la hipótesis que se desarrolla para esta investigación, de manera que se logre inferir las condiciones argumentales que lleven a la degradación de la participación conforme a criterios que se aproximen al estudio socio-jurídico en la configuración del delito. 


\section{Caracterización del lavado de activos}

Entre las distintas instituciones, entes gubernamentales y organizaciones internacionales interesadas en entender y explicar la dinámica del delito de lavado de activos, se puede reconocer el consenso de considerar al lavado de activos, como un tipo delictivo que surge en el ámbito de las redes nacionales y trasnacionales de crimen organizado, las cuales en el desarrollo de sus actividades, generan la necesidad de blanquear o legalizar dichos dineros a partir de acciones encaminadas a introducir sus dineros acumulados en actividades ilícitas, en actividades legales para camuflar su procedencia.

Aun cuando se hace referencia a redes de crimen organizado, para entidades como la Superintendencia Bancaria de Colombia (1998), hoy Superintendencia Financiera, el lavado de activos proviene en su gran mayoría de la actividad del narcotráfico, que al ser combinado con otros tipos delictivos, amplía y por lo tanto dificulta su investigación y persecución, planteando la inquietud respecto a cómo se puede lograr combatir esta actividad ilícita, sin afectar la libertad de intercambio económico que se establece para los distintos tipos de mercados.

La Superintendencia en mención, considera acertado caracterizar el delito de lavado de activos, como un acto o una serie de operaciones, por las que se busca dar apariencia lícita, a los ingresos provenientes de actividades delictivas, alertando sobre la posibilidad que todos los sectores de la economía, pueden ser infiltrados, 
aun así, no duda en destacar ciertas actividades, como son; "las actividades comerciales especialmente los negocios de alta liquidez (...), y el comercio exterior, así como aquellas actividades económicas que permiten movilizar y/o producir grandes recursos" (Superintendencia Bancaria de Colombia, 1998, pp. 19).

Si bien lo anterior permite lograr una primera caracterización del lavado de activos, corresponde en lo que sigue brindar un panorama más disgregado de la manera como se materializa este tipo delictivo, considerando diversos factores asociados al contexto en el que se produce, actores involucrados, medios de realización y actividades desarrolladas, para finalmente lograr, una descripción más detallada de esta figura criminal, que lleve a la mayor rigurosidad y profundidad el estudio jurídico que se propone de la misma.

\section{Contexto socio-económico del lavado de activos}

El lavado de activos, es un delito que tiene consecuencias directas e indirectas sobre distintos sectores y ámbitos sociales de los lugares en que se produce, afectando no sólo a quienes cometen y participan en el ilícito sino también de manera contextual, a la sociedad donde se lleva a cabo la conducta, en el sentido de los efectos negativos que esta produce, en términos de seguridad, convivencia social y sanidad económica, a su vez que trastocan las relaciones socio-económicas de la población en general. 
De manera específica, se puede atribuir a esta conducta delictiva, efectos asociados a la distorsión monetaria, efectos adversos en la tasa de cambio y balanza comercial, fomento de la competencia desleal, corrupción, desincentivo al mercado transaccional real, escenarios de incertidumbre para la toma de decisiones en materia de política monetaria y fiscal, desmejora en la credibilidad de las reglas de juego de los mercados, entre otros, que se suman a las propiamente conductas delictivas que se tipifica en la realización del ilícito (Suárez y Hurtado, 2014).

La manera como este delito conduce a unas consecuencias sociales negativas son evidentes, en lo que resulta siendo una cadena de relación necesaria entre el dinero y la ilegalidad; "en la medida que las actividades ilegales aumentan, tiene que hacerlo, también, el lavado de dinero" (Caballero y Amaya, 2011, pp. 302), convirtiendo el mismo, en un delito conexo de los tipos delictivos de gran alcance económico, que vienen asociados a la perpetración de distorsiones y alteraciones sociales en las comunidades donde se producen estos delitos.

\section{Organizaciones criminales}

El crimen organizado trasnacional en Colombia se asocia en sus inicios a los carteles de Medellín y Cali quienes fueron en sus momentos los mayores productores de drogas en el mundo y que les valió ser un blanco estratégico para las acciones del Estado colombiano y países asociados en la lucha contra las drogas, que luego se extendió a organizaciones narco-paramilitares y grupos 
armados ilegales (Thoumi, 2012). La acción institucional frente a la acción de las organizaciones criminales, ha sido direccionada desde el rediseño de la política penal contra el crimen organizado, de modo que:

Durante las últimas tres décadas, el Estado colombiano ha entendido el tráfico de drogas como un problema de seguridad nacional que debe ser enfrentado por medio de la fuerza. El sistema penal ha desempeñado un papel fundamental como punta de lanza de la lucha contra las drogas. La criminalización de las actividades relacionadas con estas ha sido el principal rasgo de la política criminal. La creación de nuevos delitos, el aumento de penas, el otorgamiento de facultades judiciales extraordinarias a entes administrativos, la limitación de las garantías procesales, la reducción de los beneficios penales y la persecución de los bienes del narcotráfico son algunas de las medidas introducidas de manera recurrente para fortalecer el sistema punitivo del Estado y reducir la violencia e impunidad asociadas al tráfico de estupefacientes. (Iturralde y Ariza, 2011, pp. 271)

Al establecer acciones contra el crimen organizado, tanto Colombia como muchos otros países, han considerado fundamental generar acciones encaminadas a incautar bienes y dineros provenientes de estas actividades, por lo que la lucha contra las drogas y otros tipos de delitos asociados al crimen trasnacional, tiene en el lavado de activos, la categorización como delito conexo que se debe erradicar para lograr acciones efectivas en relación con estos crímenes principales. 


\section{Financiación del terrorismo}

La financiación del terrorismo, se puede entender como el direccionamiento de recursos provenientes de distintos ámbitos para el sostenimiento o funcionamiento de individuos o grupos, quienes se les imputan delitos asociados al terrorismo ${ }^{1}$ (Consejo Nacional de Política Económica y Social [CONPES], 2013). Su mención se hace, en consideración de la relación en la lucha institucional que establece el Estado colombiano contra el crimen organizado y trasnacional, para lo cual ha configurado el documento de política CONPES 3793, que define la Política Nacional Anti Lavado de Activos y Contra la Financiación del Terrorismo - ALAVCFT, expedido en 2013.

Para el Estado colombiano, la cadena de prevención, detección, investigación y juzgamiento del lavado de activos y la financiación del terrorismo, pasa por la lucha fundamentalmente contra organizaciones criminales de delincuencia transnacionales, organizaciones guerrilleras que comenten actos de terrorismo, Bandas Criminales [BACRIM] dedicadas al narcotráfico, y diferentes

\footnotetext{
${ }^{1}$ Por terrorismo se asume como la actividad delictiva que de manera grupal o individual se ejecuta, para generar un estado de zozobra y terror en la población en general o en una parte de ella, a través de actos que ponen en peligro la vida, la integridad física o la libertad de las personas, las edificaciones, medios de comunicación, transporte, procesamiento o conducción de fluidos o fuerzas motrices, valiéndose de medios capaces de causar estragos (Ley 599 de 2000, artículo 343).
} 
grupos armados al margen de la ley, que destinan una parte de sus recursos obtenidos para su sostenimiento y funcionamiento, pero que al igual que usan el mecanismo de blanqueo de capitales, para legalizar otra parte de los recursos que obtienen de su actuar ilegal (CONPES, 2013).

\section{Tecnología e informática en el lavado de activos}

El continuo crecimiento de la economía y los mercados, ha llevado a que sean cada vez más las transacciones económicas que se puedan dar en el marco del aumento de las capacidades adquisitivas y de producción de las sociedades, y esto directamente ha repercutido, en el aumento de los tipos y modalidades de intercambio económico, en un circuito que, en lo fundamental, ha operado sobre el uso efectivo de evolucionadas tecnologías que hacen uso de los recursos informáticos.

Para Blanca Antolinez (2009), resulta preocupante que en la misma carrera de avance de la tecnología, se encuentra también la carrera que convoca a la delincuencia informática en la manipulación y operación indebida de los cada vez más sofisticados métodos e instrumentos para la realización de transacciones económicas en el ciberespacio, no sólo para cometer delitos tales como el acceso abusivo u obstaculización a los sistemas informáticos, interceptación de datos, daño informático, entre otros, sino también para el desarrollo de actividades delictivas que 
tienen sus orígenes en la economía real o en las economías ilegales, y que usan los recursos informáticos para aparentar un contendido de legalidad en las mismas.

Lo anterior conduce a señalar que, en tanto aumentan los mecanismos transaccionales en el mundo real y aún más en el mundo virtual, se complejizan a su vez los controles de legalidad que las autoridades deben establecer sobre estos procesos de intercambio económico, lo cual da paso a la relevancia del debate en torno a las estrategias y mecanismos sobre los que se deben apoyar las autoridades competentes, para logra de una parte identificar, y de otra sancionar a quienes conciertan en el desarrollo de actividades económicas sin una satisfacción legal:

(...) semejanzas que se manifiestan entre el funcionamiento de las organizaciones criminales y el de las modernas sociedades mercantiles, toda vez que adoptan como punto de referencia los modelos y las estructuras del mundo de la industria y de los negocios. Factores tales como la racionalización en el empleo de los medios personales y materiales de que disponen, la vocación de permanencia vinculada a un fin global de naturaleza predominante económica, la expansión de la actividad a otras áreas geográficas, la progresiva interrelación con otras entidades colectivas o individuales, la tendencia a reinvertir una parte de los beneficios, etc. han llevado a hablar a muchos autores de una auténtica "industria del crimen". No en vano se ha llegado a considerar la actividad de estos clanes como verdadero estado superior del capitalismo, en la medida en que a 
través de ellos se persigue el mayor provecho, la máxima circulación de riqueza, el mayor rendimiento de las inversiones y el total anonimato de los que intervienen en las operaciones. (Caparrós, 1998, pp. 43-44)

Por lo anterior, no se puede dejar de prever un escenario complejo en la identificación operativa del delito de lavado de activos, por cuanto se puede identificar una estructura funcional que, tanto desde el escenario transaccional virtual, como en el de la economía real, trastoca los circuitos ilegales de comercio, lo cual amplia el panorama para la determinación de la punibilidad. A partir de esta complejidad en su configuración, es que se debe dar lugar a la caracterización de la tipicidad del delito, la imputación, culpabilidad, unidad o pluralidad del delito y la determinación de la existencia de concurso en la lectura jurídico-penal de la conducta.

\section{Lavado de activos en instrumentos financieros y comerciales}

La canalización de dineros a través de instrumentos financieros, es una de las estrategias más usadas por el crimen organizado para el lavado de activos, por esto, la Oficina de las Naciones Unidas contra la Droga y el Delito [UNODC] (2011) elaboró un informe en el que pone de manifiesto las alertas que se deben tener en cuenta a la hora de hacer seguimiento a la actividad delictiva que incursiona en el sistema bancario, indicando al respecto que el lavado de activos puede ser 
identificado al momento que se genera la apertura de productos financieros, registro de firmas, depósitos, consignaciones y transferencias, y por ello, la recomendación de hacer seguimiento, en caso de identificar inconsistencias.

Tanto los instrumentos financieros más convencionales, el caso de las cuentas de ahorro y corriente, certificados de depósito, tarjetas de crédito, tarjetas prepago, giros internacionales y préstamos, como los menos convencionales, entre los que se encuentran negocios fiduciarios, bursátiles, de comercio exterior; pueden servir para lavar activos. De allí, lo atractivo que tiende a ser el sector financiero para la economía ilegal, en aras de la legalización de dineros; máxime, si se revisa que la banca por internet ha ampliado los canales operacionales, lo cual le facilita a las redes delincuenciales la legalización de sus fondos (Unidad de Información y Análisis Financiero [UIAF], 2013).

\section{Paraísos fiscales}

Existen lugares en el mundo, que resultan atractivos para el manejo de cantidades considerables de dinero, puesto que no existe una legislación severa o la fiscalidad es baja o nula respecto al movimiento de capitales, o controles que se establecen sobre los orígenes de los fondos, como igual sucede con la actividad societaria, de manera que se reconocen beneficios, como los del secreto bancario y bursátil, que les da el calificativo de paraísos fiscales (Sánchez, 2002). 
Aun cuando se establecen ciertas generalidades respecto a la designación de un territorio o país como paraíso fiscal, se debe mencionar que las ventajas o exenciones no son las mismas en todos estos lugares, así, a modo de ejemplo, se encuentra lugares como Islas Caimán o Isla Bermuda, donde no hay tributación sobre los fondos, en Panamá, Jersey o Gibraltar, se gravan únicamente los fondos que provengan de actividades desarrolladas en el propio territorio y no se tienen en cuenta los ingresos extraterritoriales, o Chipre y Malta que si los gravan, pero a tasas muy bajas, y hay otros países como Luxemburgo, Austria, Liechtenstein o Países Bajos, que establecen privilegios de exoneración impositiva para ciertas operaciones (Sánchez, 2002).

Según el autor, en 2002 de acuerdo a un Informe del Banco Mundial, los paraísos fiscales alcanzaban a concentrar en sus sistemas financieros casi 1,5 trillones de dólares, con una importante participación de Reino Unido, Hong Kong e Islas Caimán, que los llevaba a ser considerados los principales offshore centers del mundo (Sánchez, 2002), en operaciones basadas en la banca tradicional, pero sobre todo en la banca electrónica, por la cual difícilmente se puede evidenciar la procedencia de los activos de una actividad real y legal, en el marco de las normas aplicables a los territorios desde los cuales provienen los dineros.

En este sentido, lo más común es encontrar un circuito ilegal de actividades, por las que se busca blanquear los dineros que se generan por dichas actividades delictivas, siendo común que estos dineros pasen a empresas fachadas que son las encargadas en este caso de lavar o blanquear el dinero, y este finalmente resulta 
siendo depositado en el sistema financiero, particularmente en entidades donde por su ubicación, se goza de preferencia fiscal y tributaria. Posteriormente, estos dineros suelen ser regresados como dinero de origen legal, en los países donde se encuentran los autores intelectuales y materiales de los ilícitos.

\section{Las remesas en el lavado de activos}

Para poblaciones de alto flujo migratorio como la colombiana, las remesas resultan siendo un ingreso que se estima, ocupa una posición considerable en el agregado del PIB, razón por la que no se debe desconocer la existencia de acciones desde la ilegalidad, que se apoyen en las remesas como canal para la incursión de capitales en la economía nacional, más aún, si se entiende como lo establece Ximena Cadena y Mauricio Cárdenas (2004), una falta de claridad sobre cuánto es el valor exacto que desde el extranjero de manera legal se envía al país vía remesas.

Este es un elemento que no deja de preocupar si se considera la existencia de un conflicto armado y la existencia de una economía de producción y tráfico de droga que recoge parte importante de su actividad delictiva en el exterior, lo cual obliga a las autoridades financieras y de trabajo en contra del lavado de activos, a profundizar en los mecanismos que conduzcan no sólo a evitar que el sistema de remesas sea vulnerado por la actividad delictiva, sino también a generar mayores controles sobre las entidades financieras que prestan el servicio de recepción y envío de giros internacionales (González, 2005). 
Si las entidades financieras con amplios márgenes de control son vulneradas por las redes delincuenciales, no se puede esperar menos de las casas de cambio, por esto, se hace necesario establecer estrategias conjuntas que unan a la institucionalidad en la lucha contra el lavado de activos, con aquellas entidades encargadas de prestar un servicio de giros desde el exterior, que bien sirve a muchas familias en el país a través de fondos originados legalmente por personas fuera de Colombia y que son enviados por este mecanismo.

\section{Sector notariado}

La función del notario en el marco delegatorio que le acude en representación del Estado, es dar fe pública de los actos civiles y mercantiles realizados por terceros, entre los cuales se encuentran aquellos contratos o acuerdos, que involucran la cesión de bienes y la expedición de escrituras respecto a la propiedad o posesión de bienes, operaciones notariales cuya información debe ser recaudada y reportada a la UIAF, en virtud de las obligaciones de reporte previstas en los artículos 3 y 11 de la Ley 526 de 1999, modificada por el artículo 4 de la Ley 1121 de 2006.

Tanto la UIAF como la Superintendencia de Notariado y Registro, hacen eco en el hecho de generar alertas en la medida que se identifique entre otras cosas, que las operaciones notariales realizadas por un usuario, no sean consistentes con la actividad económica que este desarrolla, compras y ventas sucesivas del mismo bien en periodos cortos de tiempo, operaciones de personas naturales que 
consideren grandes sumas de dinero en nombre de clientes o fidecomisos, pagos de algunas de las partes por parte de un tercero, constituciones de sociedades por parte de menores de edad, personas impedidas $u$ organizaciones de difícil identificación, sobre las cuales y a consideración del notario, se pueden reportar como operaciones sospechosas.

Aunque las notarías no pueden impedir los resultados jurídicos de las operaciones que se realizan, sí es competencia de estas diseñar mecanismos de prevención de actividades de lavado de activos y financiación del terrorismo que logren minimizar los considerados factores de riesgo y los riesgos asociados, razón por la cual queda a consideración de las notarías, revisar los niveles de exposición y efectuar los Reportes de Operaciones Sospechosas a la UIAF cuando se considere pertinente (UIAF; Superintendencia de Notariado y Registro, 2013).

\section{Organización internacional contra el lavado de activos}

En atención a las múltiples modalidades delictivas por las que se puede configurar el delito de lavado de activos incluyendo su conexidad, es que ha hecho carrera en la comunidad internacional la tarea de instar a los países en el adelanto de una lucha en diferentes frentes para combatir el delito de lavado de activos o blanqueo de capitales. Es así, como en 1989 se crea el Grupo de Acción Financiera Internacional [GAFI], cuyo mandato es el de; "fijar estándares y promover la implementación efectiva de medidas legales, regulatorias y operativas para 
combatir el lavado de activos, el financiamiento del terrorismo y el financiamiento de la proliferación y otras amenazas a la integridad del sistema financiero internacional" (Grupo de Acción Financiera de Sudamérica [GAFISUD], 2012), organismo internacional que en 1990, expediría las Recomendaciones GAFI para la lucha contra el lavado de activos y financiación del terrorismo.

Estas recomendaciones, parten como lo explicó en su momento el GAFISUD (2012) - hoy Grupo de Acción Financiera de Latinoamérica [GAFILAT] -, de la realización de acciones a nivel nacional que permitan la protección del sistema financiero internacional en lo que respecta al tránsito ilegal de capitales monetarios, de donde resulta el lavado de activos derivado del tráfico de drogas, aunque, en el entendido que la soberanía jurídica conduce a que cada Estado tiene para la lucha contra estos delitos medidas precisas pero divergentes en términos de las caracterizaciones penales de los delitos, lo que se acude es a definir unos estándares que se recomienda a los países miembros, adaptar a sus disposiciones normativas vigentes en la materia, que esencialmente el GAFI, citado por el GAFISUD (2012, pp. 6), recoge en estos seis objetivos de implementación normativa:

- identificar los riesgos, y desarrollar políticas y coordinación local;

- luchar contra el lavado de activos; financiamiento del terrorismo y financiamiento de la proliferación; 
- aplicar medidas preventivas para el sector financiero y otros sectores designados;

- establecer poderes y responsabilidades (por ejemplo. autoridades investigativas, de orden público y de supervisión) y otras medidas institucionales;

- mejorar la transparencia y la disponibilidad de la información de titularidad de beneficio de las personas y estructuras jurídicas; y

- facilitar la cooperación internacional

Esta tarea, que como ya se ha dicho, inicia en el paso de la década de los ochenta a la década de los noventa, siendo revisada nuevamente en 1996, en atención a las cambiantes técnicas que para el tráfico de drogas y lavado de dinero se estaban dando, sin embargo, acciones reales de cambio en este referente internacional, se dieron solo hasta 2001, momento en el que el GAFI incluye el financiamiento de actos y organizaciones terroristas como parte de los fines del lavado de capitales generando al respecto ocho Recomendaciones Especiales, luego extendidas a nueve, sobre el financiamiento del terrorismo (GAFISUD, 2012).

Señala el GAFISUD (2012), hoy GAFILAT que a 2003, el conjunto total de recomendaciones tanto iniciales como las anexadas, ya ajustadas a las nuevas amenazas globales, habían sido ratificadas por más de 180 países, lo cual las convierte en el referente global de acciones a adelantar en la lucha contra el lavado 
de activos y el financiamiento del terrorismo, -o Régimen Anti lavado de Activos y Contra el Financiamiento del Terrorismo [ALA/CFT]-, las cuales también incluyen, recomendaciones en materia de cooperación con los organismos regionales y organismos observadores, tales como el Fondo Monetario Internacional, Banco Mundial y las Naciones Unidas.

En lo que corresponde a América Latina, se debe señalar que han existido cambios institucionales como lo es el paso en 2010 del GAFISUD a GAFILAT, del que hoy son parte Argentina, Bolivia, Brasil, Chile, Colombia, Ecuador, Paraguay, Perú, Uruguay, Guatemala, Honduras, México, Nicaragua, Cuba, Panamá y Costa Rica; estos últimos países asociados entre 2010 y 2013, antes pertenecientes al Grupo de Acción Financiera del Caribe [GAFIC], lo cual conlleva necesariamente al cambio del nombre institucional (Goite y Medina, 2015).

Si bien la acción institucional internacional, se ha adelantado de la mano con un número importante de países que se han aliado para combatir la actividad delictiva del lavado de activos, al otro lado del escenario también se identifica la extensión de esta forma delictiva, presente tanto en contextos reales como virtuales, asociada con distintos tipos de economías ilegales, principalmente del narcotráfico, que complejiza la tarea respecto a su determinación y a la configuración del delito.

Generada hasta aquí la posición respecto a los múltiples escenarios sobre los cuales se puede apoyar la comisión del delito de lavado de activos, lo que sigue a continuación es revisar los contextos y mecanismos por medio de los cuales se 
produce el lavado de activos, y precisar los momentos en los cuales se debe generar alerta ante la posibilidad de manipulación para la incursión legal de dineros obtenidos a través del actuar delincuencial.

En consecuencia, el siguiente aparte del documento busca presentar distintos métodos por medio de los cuales se puede presentar lavado de dinero, reconociendo como elemento clave, que en el lavado de activos, el sistema financiero cuenta con un papel central en la medida que no sólo es el medio para darle circulación a ese dinero espurio en una economía en particular, sino también porque es por medio de este que muchas de estas cantidades de dinero terminan en el exterior, en los ya referidos paraísos fiscales. 


\section{Elementos normativos del lavado de activos en Colombia y supuestos punibles de la complicidad}

Son diversos los escenarios y modalidades delictivas que se identifican en la configuración del crimen organizado trasnacional, motivo que conduce a establecer, que en la determinación del delito de lavado de activos se pueden considerar distintos tipos de conductas consumadas, prescribiendo así, los tipos penales sobre los que se imputan los cargos delictivos. Lo anterior, hace pertinente profundizar en su caracterización, con el fin de evidenciar más claramente el modus operandi como se produce y desarrolla esta actividad al margen de la ley.

En materia penal, las distintas vías por las cuales se puede configurar el delito de lavado de activos, traídas a colación en el capítulo anterior, deja entrever la posibilidad conforme a la cual la culpabilidad, no siempre debe recaer en el sujeto activo del delito, ya que se puede contemplar una plurisubjetividad punitiva, que lleve a identificar la participación de determinador y cómplice, conforme a lo reglado en el Código Penal, artículo 30, siendo este el escenario que se quiere despejar en el actual capítulo.

La consideración central de lo que sigue a continuación, recae en la caracterización de la complicidad en el delito de lavado de activos, indagando al respecto la divergencia que, en este tipo de delito, se puede dar del determinador y el interviniente, contextualizado desde la configuración punitiva del mismo. Por ello, 
en un primer momento se expone la caracterización normativa que sigue el delito de lavado de activos, estableciendo las transformaciones normativas dadas a este delito en los últimos veinte años, con ocasión de la necesidad generada sobre la caracterización y penalización más certera de los sujetos activos participes de esta conducta.

En un segundo momento, una vez identificados los elementos asociados a la conducta punible, se aborda la complejidad social que se sugiere, debe ser tenida en cuenta en la imputación del delito, al considerar que el contexto social, conduce a situaciones que desde una visión socio-jurídica, conllevan a la complicidad. Lo anterior con el fin de ahondar en el problema jurídico propuesto, respecto a la posibilidad de contemplar la complicidad penal en el delito económico de lavado de activos, para establecer una primera entrada que permita ir generando elementos para resolver el problema jurídico que se plantea con ocasión del presente trabajo investigativo, a saber; ¿Cuáles son las posibilidades para establecer la complicidad en el delito de lavado de activos?

\section{Normatividad colombiana sobre lavado de activos}

La proliferación del narcotráfico en el país a partir de la década de los ochenta, generó un mayor flujo de capitales derivados de actividades ilícitas, que terminaron transformando estas organizaciones, en estructuras delictivas con ejércitos privados y un gran control sobre distintos territorios, en los que predominaban economías 
ilegales asociadas al narcotráfico, la extorsión y el contrabando (Thoumi, 2012). De allí se desprenden, los motivos estructurales que dan paso a la aprobación de la Ley 30 de 1986, o Estatuto Nacional de Estupefacientes, que establece como delito grave, el cultivo, conservación y financiación de plantaciones destinadas a la producción de cocaína, morfina, heroína o drogas ilegales, así como el transporte, almacenamiento, conservación, elaboración, oferta, venta, adquisición, financiación o suministro de este tipo de drogas.

La ley en comento, estableció sanciones sobre el uso de bienes muebles e inmuebles para la elaboración, almacenamiento, transporte, venta o uso de estas drogas así como la posesión ilegal de elementos que sirvan para su procesamiento, entre ellos, éter etílico, acetona, amoníaco, permanganato de potasio, carbonato liviano, ácido clorhídrico, ácido sulfúrico, diluyentes, disolventes u otras sustancias destinadas para este fin (artículo 20 de Ley 365 de 1997, que modifica el artículo 43 de la Ley 30 de 1986).

Posteriormente, se expide el Decreto 1856 de 1989, que del artículo $7^{\circ}$ del Decreto extraordinario 2266 de 1991, establece como legislación permanente el artículo 6 del Decreto 1856, por medio del cual, se penaliza la prestación del nombre para adquirir bienes con dineros provenientes del delito de narcotráfico o de actividades conexas, derivando en la determinación delictiva del testaferrato, que antes abocaba en su imputación al encubrimiento por receptación. 
En 1989, se emite al igual el Decreto 1895 donde se tipifica el delito de enriquecimiento ilícito en particulares, en el contexto político del Estado de Sitio, estableciendo en tanto una transitoriedad determinante de la conducta punible, que en la revisión de la Corte Suprema de Justicia sobre la norma, se especificó, su referencia exclusiva a los dineros provenientes de las actividades del narcotráfico y conexos, en una posición que variaría normativa y jurisprudencialmente en los años siguientes.

Una vez entró en vigencia la Constitución de 1991 y teniendo la obligación el País de dar cumplimiento a lo reglado por la Convención de las Naciones Unidas contra el Tráfico ilícito de estupefacientes y sustancias sicotrópicas, suscrita en Viena el 20 de diciembre de 1988 y aprobada en Colombia, mediante la Ley 67 de 1993, se dio paso a la tipificación del lavado de activos como una forma de encubrimiento, lo cual condujo a la modificación del artículo 177 del Código Penal de 1980, ello de conformidad a la Ley 190 de 1995, conocida como Estatuto Anticorrupción.

No obstante, se debe precisar que en la tipificación del delito de lavado de activos, en un primer momento, se utilizó la figura señalada en el Código Penal, del delito de encubrimiento, adicionándosele una serie de verbos rectores, con la finalidad de ampliar las posibilidades de sanción e incluyendo algunos agravantes (Hernández, 2009). 
La ley 190 de 1995, fue modificada por la Ley 365 de 1997 y ésta a su vez por la Ley 747 de 2002, por medio de las cuales se han adicionado otros delitos subyacentes en el lavado de activos como son: el tráfico de armas, delitos financieros, delitos contra la administración pública o los que se derivan del concierto para delinquir, en una ampliación de las connotaciones delictivas del lavado de activos, para su efectiva persecución.

En materia financiera, la anteriormente mencionada Ley 365 de 1997, por medio de sus artículos 21, 22, 23, 24 y 25, hizo adiciones al Estatuto Orgánico del Sistema Financiero, Decreto 663 de 1993, posteriormente modificado por la Ley 795 de 2003, para endurecer las sanciones contra personas y entidades vigiladas por la Superintendencia Bancaria, que autoricen o ejecuten actos violatorios en contra de los parámetros legales que deben seguir en sus funciones y entidades.

Se debe al igual hacer mención, a numerosas resoluciones expedidas por la Superintendencia Bancaria, hoy Superintendencia Financiera, en la que se resalta la Circular Externa 007 de 1996 o Circular Básica Jurídica, que se convierte en la principal directriz para las entidades vigiladas por esta Superintendencia, dado que es por esta que se crea el "Sistema Integral para la Prevención del Lavado de Activos - SIPLA", instando a las entidades a crear códigos de conducta y manuales de procedimiento, para realizar controles y reportes sobre las transacciones en efectivo. 
Igualmente, en función de estas normas y otras expedidas en el mismo periodo, se generan distintas estrategias encaminadas a la lucha contra este delito, que a su vez da paso al fortalecimiento de distintos mecanismos de cooperación institucional, en lo que en adelante se fijarían como rutas mancomunadas de trabajo institucional, para luchar no sólo contra el lavado de activos, sino también contra otros tipos de delitos fiscales y económicos conexos (Cusgüen, 2005).

Aun con lo anterior, la formulación de dichas normas no evitó la proliferación de las denominadas pirámides, DRFE (dinero rápido, fácil y efectivo) y la más mencionada DMG, de David Murcia Guzmán, cuyo efecto social y económico produjo que en virtud del Decreto 4333 de 2008, el Presidente de la República, declarara el Estado de Emergencia Social en todo el territorio nacional por el término de 30 días, prorrogado por otros 30 días por el Decreto 4704 de 2008, el cual fue declarado inexequible por la Corte Constitucional, mediante sentencia C-254 de 2009, llevando al Gobierno Nacional a expedir el Decreto 4449 de 2008, que había adicionado el artículo 325A al Código Penal.

Dicha norma había sido adicionado por el artículo 2 del Decreto 4449 de 2008, el cual fue declarado inexequible por la Corte Constitucional. Bajo la necesidad de regulación, se aprobó luego la Ley 1357 de 2008, mediante la cual se modificó el Código Penal y fue adoptada como legislación permanente las modificaciones introducidas a través del Decreto 4449 de 2008, convirtiendo estas disposiciones, en normativa penal vigente. 
Como consecuencia de lo anterior, se adicionó el artículo 325A al código penal, a través del cual se crea un nuevo tipo penal, consistente en la "Omisión de reportes sobre transacciones en efectivo, movilización o almacenamiento de dinero en efectivo" a la UIAF, cuando se estuviera en la obligación de así hacerlo, generando la excepción para aquellos que tengan el carácter de miembro de junta directiva, representante legal, administradores o empleado de instituciones financieras o de cooperativas que ejerzan actividades de ahorro y crédito, a quienes se aplicará lo dispuesto en el artículo 325 del Código Penal, el cual igualmente fue modificado por la Ley 1357 de 2009.

Conceptualizando en lo recorrido la conducta delictiva del lavado de activos, consignada en el Código Penal Colombiano, ha sido varias veces ampliadas al alcance de las realidades socio-jurídicas identificadas en el ámbito de la criminalidad, de allí que se deba también hacer mención, a la modificación hecha por medio de la Ley 1453 de 2011 y más recientemente la Ley 1762 de 2015, por medio de la cual se adoptan instrumentos para prevenir, controlar y sancionar el contrabando, el lavado de activos y la evasión fiscal, que dejan finalmente el texto vigente, consignado en el artículo 323 del Código Penal:

El que adquiera, resguarde, invierta, transporte, transforme, almacene, conserve, custodie o administre bienes que tengan su origen mediato o inmediato en actividades de tráfico de migrantes, trata de personas, extorsión, enriquecimiento ilícito, secuestro extorsivo, rebelión, tráfico de armas, tráfico de menores de edad, 
financiación del terrorismo y administración de recursos relacionados con actividades terroristas, tráfico de drogas tóxicas, estupefacientes o sustancias sicotrópicas, delitos contra el sistema financiero, delitos contra la administración pública, contrabando, contrabando de hidrocarburos o sus derivados, fraude aduanero o favorecimiento y facilitación del contrabando, favorecimiento de contrabando de hidrocarburos o sus derivados, en cualquiera de sus formas, o vinculados con el producto de delitos ejecutados bajo concierto para delinquir, o les dé a los bienes provenientes de dichas actividades apariencia de legalidad o los legalice, oculte o encubra la verdadera naturaleza, origen, ubicación, destino, movimiento o derecho sobre tales bienes o realice cualquier otro acto para ocultar o encubrir su origen ilícito, incurrirá por esa sola conducta, en prisión de diez (10) a treinta (30) años y multa de mil (1.000) a cincuenta mil (50.000) salarios mínimos legales mensuales vigentes.

La misma pena se aplicará cuando las conductas descritas en el inciso anterior se realicen sobre bienes cuya extinción de dominio haya sido declarada.

El lavado de activos será punible aun cuando las actividades de que provinieren los bienes, o los actos penados en los apartados anteriores, se hubiesen realizado, total o parcialmente, en el extranjero. 
Las penas privativas de la libertad previstas en el presente artículo se aumentarán de una tercera parte a la mitad cuando para la realización de las conductas se efectuaren operaciones de cambio o de comercio exterior, o se introdujeren mercancías al territorio nacional.

Con ocasión de lo anterior, se puede establecer la ampliación de una conducta delictiva que se asocia fundamentalmente a las redes transnacionales de delincuencia organizada, las cuales operan, en el ámbito de las conductas delictivas que más preocupan a los gobiernos, siendo por lo mismo, parte fundamental de la agenda internacional de los Estados en la persecución de conductas punibles.

Sara Salazar señala con respecto al tipo penal del lavado de activos, que:

(...) podemos definir como características de nuestro tipo penal su ubicación en el Título $X$ del Código Penal, en los delitos contra el Orden Económico; su tipificación como delito autónomo, de sujeto activo indeterminado, cuyo sujeto pasivo es el Estado, como titular del bien jurídico Orden Económico y Social y la inclusión en el mismo de 11 verbos rectores, que encuentran correlación en la realización de cualquier otro acto para ocultar o encubrir su origen ilícito. (2007, pp. 145).

De manera complementaria, se puede también mencionar lo expuesto por Hernando Hernández (2014), quien sintetiza de manera clara, lo sucedido en la 
legislación colombiana respecto al delito de lavados en un periodo de algo menos de veinte años, desde lo acaecido por la expedición de la Ley 365 de 1997:

Como puede observarse, el Legislador colombiano adoptó el sistema expansivo de delitos previos del lavado de activos, el cual permite incluir nuevos delitos precedentes a criterio del propio Legislador. Así, en la Ley 365 de 1997, se señalaron como punibles, de los cuales podría provenir los bienes a lavar, actividades de extorsión, enriquecimiento ilícito, secuestro extorsivo, rebelión o relacionados con el tráfico de drogas tóxicas, estupefacientes, o sustancias sicotrópicas. En las normas del Código Penal -Ley 599 de 2000-, se incluyeron como delitos previos, además de los citados, el tráfico de armas, los delitos contra el sistema financiero, la administración pública o los vinculados con el producto de los delitos objeto de un concierto para delinquir. Más tarde, con la expedición de la Ley 747 de 2002, que sanciona el tráfico de migrantes y la trata de personas, se incluyeron estos delitos como subyacentes al lavado de activos. Recientemente, el artículo 17 de la Ley 1121 de 2006, modifica el artículo 323 del Código Penal Colombiano, para incluir como delito previo del lavado de activos, la financiación del terrorismo y la administración de recursos relacionados con actividades terroristas. Finalmente, con la Ley 1453 de 2011, se introduce como delito subyacente el tráfico de menores de edad. (pp. 186-187). 
Identificados por lo anterior los verbos rectores que conducen a la conducta antijurídica del lavado de activos, lo que sigue a continuación es retratar la fenomenología del delito, desde una concepción técnico-jurídica que conduzca a reconocer los elementos determinantes del mismo, en lo que en últimas se convierte en un análisis dogmático, del que se deriva el análisis mismo de la complicidad, que conduce la presente investigación.

\section{Elementos de la figura delictiva del lavado de activos}

Es claro que la atención de las autoridades se centraba fundamentalmente en los mencionados delitos subyacentes del lavado de activos; en este sentido, más que la persecución del lavado de dinero, la política criminal se centraba en la

persecución de delitos graves como el tráfico de drogas, el descubrimiento e incautación de los dineros espurios, hacían parte del castigo por la motivación económica, que por la comisión misma del delito subyacente; panorama que hoy no se refleja en las distintas legislaciones penales de los países.

El lavado de activos, actualmente y para el caso preciso de la legislación colombiana, se mira desde una perspectiva de delito independiente al delito subyacente, condición que hace necesario, profundizar en la caracterización normativa de este delito. Por lo mismo a continuación, se exponen los elementos referenciales punitivos de esta conducta, en la que se hace especial énfasis sobre 
la determinación de la complicidad, considerando la estructura lógica y normativa de esta posibilidad jurídica.

\section{Bien Jurídico Tutelado}

Como se anotaba en la revisión normativa, el bien jurídico tutelado por el precepto penal es el Orden Económico y Social que persigue el Estado, que entre otras cosas se manifiesta en el curso legal de la moneda nacional y las divisas extranjeras que se manejan en el sistema bancario, financiero y economía de intercambio en lo extenso del territorio nacional, lo que a su vez lo hace sujeto pasivo de la conducta de lavado de activos. En la medida que exista un flujo y encaje de divisas extranjeras por mecanismos ilegales, ingresadas a la economía nacional a través de las actividades delictivas señaladas en el artículo 323 del Código Penal Colombiano, se genera un deterioro a la sanidad monetaria del país, que se enmarca en la Constitución Política de los colombianos.

Recogiendo la revisión hecha en la primera parte del documento, se dimensiona que en efecto la capacidad de acción y daño del lavado de activos, justifica las medidas institucionales que se toman tanto en el orden interno como externo. Para el caso nacional, la permeabilización mafiosa del sistema financiero, la distorsión de la economía y sus consecuencias nefastas para el logro de una economía sana y vigorosa, que impulse el desarrollo del país, acompañado todo ello con el profundo daño al componente social, resultan más que justificables las 
medidas que se han tomado y deberán tomarse, para serle frente a este flagelo, asociado al lavado de activos toda una cadena criminal que conlleva al deterioro del orden social, bien jurídico junto con el económico, que se vienen violentado con las acciones criminales en este sentido.

Frente a este precepto, se debe hacer mención a que, en los ordenamientos jurídicos de otros países, el bien jurídico tutelado es el de la seguridad jurídica, la salud, y la administración pública (Durrieu, 2011), esto, teniendo en cuenta como se afirma en la primera parte del actual documento, la injerencia que en la comisión de esta actividad delictiva puede tener la administración pública a través de sus funcionarios, en detrimento del correcto funcionamiento de la misma. Se considera, este es un elemento de discusión que merece igual profundidad analítica a la propuesta sobre la participación, sin embargo, para no desviar la atención del documento, se deja mencionada esta discusión jurídica que bien se puede retomar en próximos documentos.

\section{Sujeto activo}

Siguiendo en artículo 323 del Código Penal, la conducta de lavado de activos puede ser desarrollada por cualquier persona sin que exista una cualidad específica para el desarrollo de la misma, lo que hace que la conducta se enmarque en un tipo penal de sujeto activo indeterminado, en la que se halla acciones encaminadas a 
consumar el delito, para obtener un beneficio personal o de terceros, de carácter económico o material.

El acto ilícito es necesariamente doloso, consciente y voluntario, con un propósito determinado, animus lucrandi, que es el móvil que induce al agente a la realización del ilícito, y aunque, no conozca con certeza la procedencia del dinero, es presumible que su procedencia no es lícita y por lo mismo la necesidad de blanquear dichos dineros, en lo que se puede configurar como tipicidad subjetiva del agente que despliega la conducta.

\section{Participación Delictiva}

En la figura delictiva del lavado de activos, la participación se establece por intermedio de un agente que despliega la conducta, por la cual se genera el ingreso de dineros al sistema financiero o monetario de la economía legal, transfiriendo o repatriando los capitales ilegales en el circuito económico legal del país, lo cual se puede dar, a través del encubrimiento o la complicidad, siendo esta la modalidad participativa que se sugiere adaptar en este delito, contrario al tratamiento que se da en la actualidad, donde la redacción del tipo penal, restringe únicamente a la modalidad de autoría y coautoría.

Queriendo dar lugar a una nueva aproximación de la participación, a continuación, se acude a exponer las tipologías de configuración del delito de lavado 
de activos, las cuales se presume que analizadas desde una lectura circunstancial o de proximidad con el contexto socio-jurídico, puede prever interpretaciones de la conducta delictiva en la modalidad de complicidad, que, en un aparte adicional, es estudiada para efectos de revisar su aplicabilidad para este tipo delictivo.

\section{Tipologías de configuración del delito de lavado de activos}

El sistema financiero, por la posibilidad de participes y cantidades de dinero manejadas, ofrece el mecanismo más complejo, pero a su vez el más utilizado para el lavado de dinero por parte de las redes delincuenciales trasnacionales, sin embargo, por los manejos internacionales, el sistema financiero no bancarizado abre posibilidades para la comisión del delito, fundamentalmente a través de las casas de cambio, por lo que se requiere que ambas técnicas o tipologías, sean abordadas a continuación.

\section{Estructuración, atomización o pitufeo}

Es claro que el sistema financiero se constituye en el medio más idóneo para el desarrollo de la actividad de lavado de dinero, por lo mismo el más utilizado por las redes delincuenciales para la comisión de sus acciones, a través de lo que se denominan redes para el lavado de dinero. En la actividad se busca que se involucren varias personas, a las que se les pide la apertura de cuentas bancarias, o el préstamo del nombre para el cobro de giros, recibiendo a cambio una cantidad 
ínfima de dinero y de allí la denominación que se le da de "pitufeo" (Hernández, 20009).

Las grandes cantidades de dinero se atomizan o se dividen en unas más pequeñas, con el propósito que estas transacciones no sean rastreadas por las unidades institucionales dedicadas a esta tarea como la UIAF, en casos también, se abren cuentas con cantidades bajas de dinero, que en el muy corto tiempo comienzan a generar movimientos financieros de altas sumas, y luego se convierten en inactivas o son cerradas, buscando también así, evitar la persecución institucional (Hernández, 20009).

Lo que se identifica en los anteriormente mencionados mecanismos de operación es que el movimiento de las cantidades de dinero hechos, no concuerdan con los ingresos presumibles que puedan dársele a quien actúa como titular de la cuenta, o quien presta su nombre para la realización de transacciones, considerando en ocasiones, la posibilidad de hacer la apertura del producto financiero en el exterior, para dificultar el rastreo.

Así se puede plantear que para los casos de este tipo de delitos económicos, se predique el grado de participación de quien actúa como señuelo prestando su nombre y a quien se le debería imputar cargos de coparticipación delictiva, como lo es la complicidad, teniendo en cuenta dos cosas: que en el resultado de la acción es evidente que su posibilidad de retribución no es igual a la exposición, y segundo, que existen unas circunstancias sociales en el trasfondo de la relación entre los 
partícipes, que debe resultar relevante para el operador de justicia a la hora de determinar las responsabilidades delictivas.

Lo anterior se puede considerar, si en el desarrollo del proceso del señalamiento de la acción antijurídica, se ha tenido en cuenta que la conducta del lavado de activos es la derivación de otra conducta punitiva. Esta conducta que por defecto se asocia a la procedencia ilegal de dineros, como lo es el narcotráfico o demás delitos enlistados en el artículo 323 del CP, indica que el "pitufo", que en este caso es el que realiza la acción de la transacción económica o presta a modo de titular su nombre en el producto financiero para la comisión del delito, es el que menos puede estar informado sobre la procedencia de los fondos, todo, en atención de la subordinación a la que ya se ha hecho referencia, y que puede conducir a situaciones de respeto reverencial en las que por ejemplo, se evite cuestionar la actuación en buena fe del mayor jerárquico.

La caracterización de este tipo de comisión delictiva, demanda igualmente, poner en cuestión el bien jurídico afectado con ocasión del adelanto de la acción punitiva, que aunque sea un tema que se aborde en la parte final del documento, sí conviene indicar que lo que se puede dar, más que la afectación del orden económico, es de la administración de justicia, como sucede en sistemas penales de otros países, caso particular el español que se revisará más adelante, sin que ni esto, ni lo mencionado en el anterior párrafo, le quite la condición de autonomía al delito. 
Para llegar a los argumentos que se pretenden dar en defensa de lo que anteriormente se indica, resulta necesario profundizar en el análisis jurisprudencial colombiano, para establecer en el estudio de los mismos, lo oportuno que resulta la consideración social de la configuración del delito, que sirvan como elementos argumentativos, respecto a las posiciones que anteriormente se creen acertadas adelantar.

Inicialmente se debe señalar que el delito de lavado de activos, es un comportamiento que al amparo de la jurisprudencia emanada por parte de la Corte Constitucional, goza del carácter de delito autónomo, con independencia de los delitos relacionados para la consecución de los capitales, y esto, con función de no limitar el papel del investigador judicial, no solo para hallar la conexidad del delito que de por si es tarea compleja, máxime si se tiene en cuenta que muchos de los delitos son cometidos por fuera de las fronteras nacionales. Al respecto, en sentencia de control de constitucionalidad de la Ley 1017 de 2006, por medio de la cual se aprueba el "Convenio sobre Blanqueo, Detección, Embargo y Confiscación de los Productos de un Delito", llevado a cabo en Estrasburgo el 8 de noviembre de 1990, la Corte estableció:

(...) para la configuración del delito de blanqueo de activos, resulta irrelevante que el delito base esté bajo la jurisdicción del Estado parte. Esta consideración tiene sentido si se advierte que el delito de blanqueo de activos se configura a partir de una operación monetaria que no necesariamente debe estar directamente vinculada con el 
delito que genera la ganancia. Por ello, la configuración del delito de lavado de activos es autónoma, y sólo depende de la conciencia de quien incurre en cualquiera de las conductas descritas, de que los bienes manipulados son producto o instrumento de un delito. (Corte Constitucional, Sentencia C-931, 2007).

Es claro que el delito de lavado de activos por su compleja configuración debe gozar del carácter de delito autónomo, en la medida que como ya se advertía, puede resultar para el investigador judicial ininteligible generar un nexo causal claro sobre la conducta desplegada por el sujeto activo de la conducta, no obstante, como más adelante se plantea, este no puede ser el argumento central para pasar por alto la revisión contextual del delito, en los términos de presumir la evidencia de una relación causal entre la conducta inicial que conduce a la obtención de los fondos, y la acción de lavar activos que puede llevar el sujeto o los sujetos activos de la conducta.

En lo que respecta a la caracterización punitiva de este delito, uno de los elementos claves que se ha desarrollado por parte de la Corte Suprema de Justicia, es la consideración respecto a si la imputación del delito, se debe atar a la evidencia de un delito subyacente sobre el origen de los fondos, teniendo en cuenta que la imputación no requiere una decisión judicial en firme que condicione la ilícita procedencia de los fondos, afirmando para tal fin que: 
"No es dable asociar la demostración "con certeza" de la actividad ilícita antecedente, o la "prueba" de la conducta subyacente o el requerimiento de una declaración judicial "en firme" que declare la existencia del delito base para fundamentar el elemento normativo del tipo en la conducta de lavado de activos. La Sala reitera la tesis de que lavar activos es una conducta punible autónoma y no subordinada." (Corte Suprema de Justicia, Sala de Casación Penal, Proceso 23174, 2007).

De igual manera, el tribunal ha determinado que, en este tipo de delito, no es necesario que la acusación se establezca sobre el mismo o los mismos sujetos activos a los que se les puede imputar los delitos subyacentes, por lo que nuevamente se desvirtúa, el elemento de la decisión judicial en firme sobre la tipificación de un delito subyacente, como se indica en la Sentencia 23754 de Sala de Casación Penal de la Corte Suprema de Justicia:

“(...) la jurisprudencia de esta Corte tiene sentado que aunque en el delito de lavado de activos es necesario demostrar en el proceso que los bienes objeto del mismo provienen de alguna de las actividades ilícitas a que se refiere el trascrito artículo 323, para su acreditación no es necesario, sin embargo, la existencia de una sentencia previa en ese sentido, sino que en el proceso debe estar patente esa situación, bien sea que la conducta se le cargue a quien se investiga o a un tercero, sin que esa particularidad demande una prueba específica. 
(...). Bajo esa lógica, en el presente caso, para tipificar el delito de lavado de activos, bastaba entonces la demostración de que el sujeto activo de la conducta ocultó o encubrió "la verdadera naturaleza, origen, ubicación, destino, movimiento o derecho sobre tales bienes", sin necesidad de acreditar con una decisión judicial en firme el delito de donde provenían los recursos ilícitos, pues la actividad ilegal subyacente sólo requiere de una inferencia lógica que la fundamente" (Corte Suprema de Justicia, Sala de Casación Penal, Proceso 23754, 2007).

Lo anterior sirve para indicar, que como se sigue el método de juzgamiento actualmente del delito de lavado de activos en el país, hay poco espacio para la valoración circunstancial del hecho, en el sentido de validar si en evidencia el delito fuente, fuese o no de conocimiento del imputado o los imputados del delito de lavado de activos, es una conducta realizada en comisión o por lo menos en conocimiento de estos, o por el contrario, reconocer un desconocimiento y la obediencia en un acto subordinado, sobre la conducta punible que se les imputa.

En la revisión de los delitos subyacentes que se configuran en el delito de lavado de activos, debe afirmarse que según el trabajo de Wilson Martínez, Paula Pardo y Omar Vera (2014), en lo corrido del periodo 2005-2013, los delitos fuentes con lo que más se relacionó el lavado de activos, hacen referencia al enriquecimiento ilícito y al narcotráfico, lo que resulta oportuno cuestionar es si, en todos los casos juzgados, existía un real conocimiento o por lo menos el indicio, de 
los delitos subyacentes por los que luego se configuró el lavado de activos, sobre todo en tipologías tales como el pitufeo.

En lo que respecta a las tipologías, Wilson Martínez, Paula Pardo y Omar Vera (2014), en el análisis que hacen de 93 sentencias para el mismo periodo (20052013), establecen que para 33 de los casos la tipología fue ingreso de divisas al país por correos humanos, seguido por 10 casos de transferencias fraccionadas de dineros ilícitos a través de giros nacionales e internacionales, y en tercer lugar 6 casos de pitufeo, lo que devuelve nuevamente la inquietud sobre la posibilidad de conocimiento del imputado, de la procedencia del dinero, o lo que puede ser aún más discutible, la amenaza latente sobre la persona para la comisión del delito.

Así, conviene revisar la legislación internacional al respecto, revisando con especial detenimiento la legislación en el caso del sistema español con el que se tiene proximidad, para contemplar figuras puestas allí no sólo en el ámbito procesal, sino también en la manera como se realiza la contextualización socio-jurídica de la conducta, en atención a la necesidad de persecución de los delitos subyacentes.

\section{Autoría}

Tradicionalmente la autoría de un delito como el lavado de activos, ha recaído fundamentalmente sobre la persona o las personas que de manera mal intencionada llevan a cabo la transacción económica por la que se perpetra el delito de blanquear capitales ilegalmente obtenidos, imputando a estos la responsabilidad 
de autoría, que al parecer hace que se pierda el interés por amplificar el tipo penal por la complicidad o la tentativa.

Si bien esto se puede exponer como resultados positivos en términos de la efectividad de la política criminal, es necesario establecer si en efecto, la persona o las personas que llevan a cabo la transacción económica son los verdaderos y únicos responsables de la comisión del delito, o por el contrario en la revisión de la amplificación de la conducta, se pueden hallar mayores responsabilidades. Para esto resulta pertinente revisar el artículo 29 del Código Penal en el que se establece que: "es autor quien realice la conducta punible por sí mismo o utilizando a otro como instrumento", señalando adicionalmente que: "son coautores los que, mediando un acuerdo común, actúan con división del trabajo criminal atendiendo la importancia del aporte", siendo este último elemento un punto esencial para la imputación del delito de lavado de activos, dada la posibilidad de configuración en algunos de los casos.

Lo que se pretende señalar es que, para el lavado de activos y su imputación, es necesario que el operador de justicia tenga en cuenta que quien realiza la transacción económica o participa con su nombre en ella, no siempre actúa mediante un acuerdo común de división del trabajo en la comisión criminal, sino que en ocasiones este acuerdo se puede más que todo dar, por una serie de consideraciones de relación social, fundamentalmente la subordinación, que debe hacer entendibles las razones que obligan a una persona o personas, a colaborar en la comisión del delito. 
Se quiere establecer que, para el delito de lavado de activos, es necesario acudir a una valoración relacional de los implicados para determinar en efecto a quien se le debe imputar la autoría y a quien la participación criminal de la complicidad, empero, aunque se proponga para un delito específico como lo es el lavado de activos, bien en algunos casos se puede hacer extensible a otros tipos penales de delitos económicos.

\section{Complicidad}

Anteriormente se hacía mención a la posibilidad de la plurisubjetividad en la comisión del delito de lavados de activos, pues como lo afirma Paola Casabianca (2009), en la parte general del Código Penal, se establecen dos tipos de dispositivos amplificadores de la conducta, que en el momento de determinar el iter criminis, puede conducir a que la misma conducta recaiga sobre personas diferentes al sujeto activo de la conducta, siendo estos dispositivos, la tentativa y la coparticipación. La complicidad se define como una modalidad de coparticipación, expresada en el artículo 30 del Código Penal, no obstante, aunque en un inicio se señalan dos categorías de participación criminal, al igual que Paola Casabianca (2009), se propone que se debe considerar que al final resultan siendo tres, a saber; determinador, interviniente y cómplice, que están supeditados a la accesoriedad de las diferentes maneras de participación en el delito. 
Por determinador, se puede indicar que esta es la persona que crea la idea criminal en el autor, ya sea por persuasión, o por coacción. Por su parte, el interviniente no es un partícipe del delito, "sino la persona que actúa en compañía del autor cualificado de un injusto propio, y ejerce el condominio con éste" (Casabianca, 2009, pp. 119). Ya en la figura del cómplice, se puede afirmar que este es un partícipe que le colabora al autor, favoreciendo la conducta antijurídica de este, aumentando las posibilidades para lesionar o amenazar el bien jurídico tutelado, desde la perspectiva que, sin su colaboración, posiblemente o de manera certera, no existiese tal lesión al bien jurídico tutelado.

Lo anterior evidencia el sistema diferenciador en la autoría que sigue el Sistema Penal colombiano; mientras que, en los sistemas unitarios al autor, se le pueden imputar diferentes modalidades de comisión del delito que recaen sobre el autor material, en Colombia, las modalidades pueden ser variadas, en las que se hallan el autor, coautor, interviniente, determinador o cómplice, identificándose para este último, cinco requisitos esenciales determinadores de la conducta (Casabianca, 2009):

- $\quad$ Existencia del autor

- Existencia de un acuerdo de voluntades previo o concomitante a la conducta del autor

- Que el aporte del cómplice consista en una ayuda que favorezca la conducta del autor

- Que el cómplice actúe dolosamente 
- Que la cooperación del cómplice sea concomitante a la realización de la conducta antijurídica o posterior a ésta por acuerdo anterior o concomitante a ella

Lo anterior conduce a indicar que en un sistema diferenciador como el colombiano, la figura del cómplice se atribuye, a quien, de manera libre y dolosa, coopera en la realización del delito doloso de otro (Gómez, 2003). Bien se podría extender la comprensión así de la autoría y la participación, resaltando la cabida de la teoría del dominio del hecho, o domino del acto, propuesta por Welzel, citado por Gómez (2003); según la cual, en los delitos dolosos es solamente autor, quien domina la realización del tipo penal, de tal suerte que se llegue a afirmar que, "el autor se diferencia del partícipe en que aquel tiene el dominio final en la producción del acto, en cambio éste auxilia al acto dominado finalmente por el autor, o incitó su decisión" (p. 1212), de tal forma, que el autor se domina la conducción del ilícito, que es una condición no atribuible al partícipe.

En este sentido, el fundamento de la punibilidad de la conducta del cómplice, recae fundamentalmente en la manera de contribución a la lesión del bien jurídico tutelado, haciendo un aporte causal al resultado antijurídico, aunque el delito se logra por la acción del autor. Se reconoce que la complicidad ha contribuido al autor para obtener el resultado antijurídico, por ello la punibilidad del cómplice es proporcional al nivel de contribución que le haya dado al autor. Precisamente en Sentencia de 2006, la Sala de Casación Penal de la Corte Suprema de Justicia señala al respecto que: 
(...) bastará conjugar elementos objetivos y subjetivos en la consumación de la conducta, para diferenciar la coautoría y la complicidad, en la medida en que para que una persona pueda ser considerada coautora de un delito, no solo se exige su voluntad incondicional de realizarlo, sino también su contribución objetiva, es decir, la importancia de su aporte en la fase ejecutiva, pues ello es lo que en últimas determina el llamado "condominio del hecho", entendiendo como "hecho" el proceso causal que con la conducta se pone en marcha.

Precisamente, como lo recuerda el Procurador delegado en su concepto, de acuerdo con la llamada "teoría del dominio del hecho", de gran utilidad para diferenciar las dos formas de participación, es autor aquél que se encuentra en capacidad" (...) de continuar, detener o interrumpir, por su comportamiento, la realización del tipo" ello de acuerdo a Claus Roxin, en su obra Autoría y dominio del hecho en derecho penal, Madrid, Marcial Pons. 1998, pág. 42. Por lo tanto, cuando son varios los sujetos que pre acordados concurren a la realización de la conducta antijurídica, para que el aporte configure coautoría se requiere que sea esencial, y que se materialice durante la ejecución típica.

De allí que solo quien domina el hecho puede ser tenido como autor; mientras que el cómplice es aquél que simplemente presta una ayuda 
o brinda un apoyo que no es de significativa importancia para la realización de la conducta ilícita, es decir, participa sin tener el dominio propio del hecho.

En este sentido, para un delito como el lavado de activos, el reconocimiento de distintos grados de punibilidad abre el espacio para declarar la complicidad como una posibilidad existente, sin embargo, para que ello resulte, es importante indagar sobre la autoría del hecho, definiendo quien efectivamente desarrolla la conducta punible, para luego establecer la coparticipación. Volviendo sobre la jurisprudencia citada, lo que se quiere plantear es que como lo ha pronunciado la Corte Suprema, la autoría viene supeditada a quien domina el hecho, es decir, tiene control sobre el mismo al punto que es este quien controla en principio que la conducta ilícita se presente o no, mientras que el cómplice, es aquel que ayuda a la realización, pero no como determinante del hecho.

Esto visto de una manera más práctica, lleva a afirmar que se pueden identificar casos en los que el autor como sujeto dominante del hecho, es finalmente, el que decide quien se ve involucrado como partícipe o autor inmediato, puesto que cuando por alguna circunstancia el sujeto que podría actuar como autor directo, no logra hacerlo, de manera simple el artífice intelectual cambia de sujeto para finalmente configurar el ilícito. Lo anterior lleva a considerar a su vez la tesis de la autoría mediata, por la cual se establece que, "el autor no siempre necesita ejecutar con sus propias manos la acción punible en cada una de sus fases, [pues 
haciendo uso de otros mecanismos u otros sujetos los puede ejecutar] conservando el dominio del hecho típico (Gómez, 2003, p. 1213).

Sin embargo, se deben tener algunos cuidados en la interpretación de lo afirmado, en el sentido que no se quiere plantear de manera abstracta la situación, sino que en la interpretación de la culpabilidad, debe ser evaluada la configuración contextual del ilícito, y en este sentido, lo que se quiere poner de relieve es la posibilidad de identificar situaciones de sometimiento o intimidación social, tal y como puede pasar en relaciones de subordinación laboral, que conducen a una persona a actuar en este tipo de situaciones, sea prestando su nombre o transportando un dinero, más por un temor reverencial, que en atención de lo dispuesto en la ley.

En lo dicho, se esboza la tesis que se quiere manejar en el actual documento, y sobre la cual se estará profundizando páginas más adelante, cuándo se aprecie cómo el ejercicio comparado sirve para nutrir los argumentos de lo propuesto, empero, se insiste en que el operador de justicia para el caso de la evaluación de la responsabilidad en un delito como el lavado de activos para el caso de la legislación colombiana, no debería pasar por alto la contextualización del delito, sobre la que se cree sería interesante evaluar, para matizar la responsabilidad, en consecuencia de una mejora en la lucha institucional contra el lavado de activos. 


\section{Normatividad internacional en el lavado de activos}

En la medida que en el lavado de activos convergen varias de las actividades ilícitas más perseguidas en el mundo, resulta necesario detenerse en dichos sistemas normativos, no sólo para el caso de las estrategias internacionales en el seno de la lucha internacional contra el delito organizado, sino también en los sistemas normativos internacionales como lo es el caso del sistema penal español, en el que se hayan elementos procesales de análisis que sirven a la explicación del delito para el caso preciso que quiere evaluarse de manera concreta en este documento, es decir, sobre la complicidad en el lavado de activos.

\section{Posible complicidad en el blanqueo de capitales desde el sistema penal español}

La sanción en la legislación española, del delito de lavado de activos o blanqueo de capitales, es relativamente reciente si se tiene en cuenta que la misma se establece su contenido específico en la Ley 19 de 1993, no obstante, desde antes el país ya venía discutiendo este asunto de política criminal, dados los contenidos de las 10 Recomendaciones del Comité de Ministros de la Unión Europea [UE], la Directiva Comunitaria 308 de 1991, las Recomendaciones GAFI, o la Declaración de Basilea expedida en la década de los ochenta (Palma, 2000). 
En el marco de los dispositivos normativos que atañen a la sanción del delito de lavado de activos, se puede hacer eco a distintos elementos que revisten pertinencia para el desarrollo del actual documento, tal y como sucede con la figura del miedo insuperable, que hace referencia a la existencia de realidades, en las cuales se puede presentar un miedo temerario que obliga al sujeto activo de la conducta a su realización, y en este sentido indefectiblemente el constreñimiento para la consumación de la conducta delictiva.

Es claro que no se puede asumir esta modalidad como complicidad, sino algo más cercano a una ausencia de responsabilidad, siguiendo la profundización que al respecto se puede hallar en documentos como el de Jaime Sandoval (2003), sin embargo, deja entrever la posibilidad sobre los contextos que conducen a la realización del ilícito, materia de análisis en este documento. Nos acogemos al planteamiento de Jose Manuel Palma (2000), quien reconoce otras conductas que conllevan a la comisión del delito de blanqueo

"El blanqueo de capitales se caracteriza, como vimos en otro momento de este estudio, por llevarse a cabo, frecuentemente, en el seno de organizaciones criminales de carácter mafioso y sumamente peligrosas, que no dudan en recurrir a la amenaza directa para conseguir sus objetivos". (pp. 623).

Por ello se presenta la posibilidad de reconocer en el sujeto activo de la conducta ausencia de responsabilidad criminal, en la medida que el miedo 
insuperable lo ha condicionado a la comisión del delito, pues de otra manera, puede estar poniendo en riesgo su integridad o su propia vida, dicho en este sentido, es importante que en algunos casos de juzgamiento de la conducta, se valore, ese miedo como condición que conlleva no por voluntad, sino por amenaza, a prestarse en la realización del ilícito, pues como lo señala José Manuel Palma:

"Así, si esas amenazas de un mal de cierta seriedad y firmeza, antijurídico e ilícito, real o imaginario, e insuperable, se traducen en actos típicos y antijurídicos de blanqueo de capitales, podría alegarse esta causa de inculpabilidad, ya que, ciertamente, no será exigible a esos sujetos un comportamiento heroico que desatienda las presiones de grupos criminales". (2000: 624).

En su texto, José Palma pone de ejemplo el empleado bancario, que es intimidado para proceder de tal manera, sin embargo, a este único ejemplo no se reducen los casos, y por el contrario se pueden hallar multiplicidad de situaciones, que en el contexto colombiano, puede ser el empleado o la empleada de servicios generales que persuadida, o actuando ante la necesidad de conservar su empleo, presta su nombre para que se abra un producto bancario, por el que finalmente resultan manejándose inmensas sumas de dinero, resultado de ilícitos realizados por mafias delictivas, siendo esto uno de los tantos casos en los cuales se puede pensar que aunque actuó como autor del delito, su culpabilidad debería ser repensada. 
Este tipo de inculpabilidad que se propone, vigente en el sistema penal español, y revisado en documentos como el de Nelly Salvo (2014), es punta de lanza para evidenciar la necesidad de contextualizar el delito de lavado de activos en su imputación, lo cual lleva a que se reconozca como se hace en el sistema de acusación español, un diferencial entre el sujeto activo de la conducta de lavado de activos y el autor de la acción previa, por el cual surge de manera ilícita el activo.

"En su momento nos ocupamos del sujeto que realizaba los actos descritos por el tipo penal concluyendo que sujeto activo del delito podía serlo cualquiera -un tipo común por esta razón-, salvo el propio autor o partícipe en el delito previo. Partiendo de esta consideración, autor del delito de blanqueo de capitales también podrá serlo cualquier sujeto -excepto, como es lógico, el que lo hubiere sido del delito previo- que, de forma antijurídica y culpable, <conjugue> los verbos de uno de los tipos del artículo 301: el que adquiera, convierta o transmita bienes, sabiendo que los mismos proceden de un delito grave, o realice cualquier acto que tenga por objeto dichos bienes y que se dirija a alguno de los fines que el mismo precepto recoge; o el que oculte o encubra la verdadera naturaleza, origen, ubicación, etc., de esos bienes". (Palma, 2000: 632).

En este sentido, en el delito de lavados de activos en la legislación española se busca generar una diferencia entre quien opera como sujeto de la conducta y el que ejecuta las modalidades de dolo según sea el caso, del autor de la misma, sin 
negar que en ambos casos existan responsabilidades penales, aunque diferenciadas en función de la participación que se le impute:

"La inadmisión del autor del delito previo como sujeto activo y, en consecuencia, autor del blanqueo, conlleva la imposibilidad de exigir responsabilidad criminal a quienes hubieren participado, de una forma u otra, en los actos de blanqueo realizados por ese sujeto. El principio de accesoriedad en la participación significa que el partícipe está obligado a responder cuando el autor haya llevado a cabo una conducta típica antijurídica -sin necesidad de que sea culpable-. Partiendo de que el autor del delito previo no puede llevarla a cabo, quien haya colaborado con él en el de blanqueo, tampoco podrá responder como partícipe. Esta situación no significa que el comportamiento desarrollado por estos sujetos quede, necesariamente, impune, pues no será infrecuente que la conducta desplegada pueda incardinarse, como autoría en el auxilio complementario del artículo $451.1^{\circ}$ del Código Penal. Bien es cierto que la pena en estos casos puede llegar a ser notablemente inferior". (Palma, 2000: 632).

En mención al acápite anterior, se vuelve a lo expuesto respecto de las tipologías que más se pueden dar en el lavado de activos en Colombia; ingreso de divisas al país por correos humanos, transferencias fraccionadas de dineros ilícitos a través de giros nacionales e internacionales y el pitufeo, resaltando que la 
judicialización de este delito en el país se da entre sujetos que, aunque colaboren en la consumación del delito y jueguen un determinado rol en el posicionamiento de la delincuencia organizada, no propiamente se les puede endilgar la autoría o coautoría del lavado de activos.

Como se ha advertido anteriormente, el miedo insuperable que se trabaja en el sistema penal español conduce a contemplar una suerte de inculpabilidad, ahora, es conveniente también hacer un tratamiento similar de las condiciones de subordinación como una especie de condicionamiento en la que el sujeto, atendiendo a la posibilidad de perder su posición en la pirámide jerárquica de una organización con apariencia de legalidad, le conduzca a tomar decisiones poco afortunadas.

Dentro de los casos de pitufeo que se dan en el sistema penal colombiano, es común encontrar a personas que atendiendo a una orden de un superior en una organización aparentemente legal -por la que se le genera una relación laboral subordinada-, y de la cual se podría igualmente predicar un temor reverencial, lleven a cabo transferencias de dinero o presten sus nombres para la apertura de productos financieros por los que posteriormente se manejan grandes sumas de dinero y que una vez descubiertos por las autoridades, el procedimiento legal acorde a nuestro ordenamiento normativo es imputarles el delito de lavado de activos, toda vez que tales conductas conllevan al perfeccionamiento del delito en mención. 
Si bien en estos casos no se pretende descartar la responsabilidad, sí se podría plantear la posibilidad tal y cómo lo ofrece el sistema español de una culpabilidad reducida, lo cual debe partir de hacer una ponderación al diferenciar la autoría de la participación bajo el grado de responsabilidad o de conocimiento con relación a la comisión del delito previo, a través del cual se obtienen los fondos, para la trasgresión de la conducta delictiva del lavado de activos. Doctrinantes como Eduardo Fabián Caparros (1998), advierten de la necesidad de conocimiento de procedencia de los fondos por parte del sujeto activo del delito sobre la conducta desplegada, en el sentido de reconocer o por lo menos intuir la procedencia de los mismos, que para lo mismo ya tendería a contemplar la coautoría:

"En efecto, el lavado de capitales sólo se puede castigar en la medida en que el sujeto activo conozca el origen ilícito de los bienes sobre los que opere. Aún más: aunque no sea preciso saber a ciencia cierta cuál fue la concreta figura cometida, ni las circunstancias específicas de orden jurídico concurrentes sobre el caso -recordemos una vez más la clásica doctrina de la <valoración paralela en la esfera del profano> recién apelada-, sí está comúnmente extendida la idea de que es preciso que el agente, al menos, sepa que los bienes de que se trate proceden de la categoría o categorías de infracciones a las que haga referencia el correspondiente tipo de blanqueo. A nadie se le oculta que éste es un dato que, ni siempre se manifiesta, ni-de darse- es fácil de probar, aún en los Estados en los que la penalización no afecte 
al lavado de fondos procedentes de una lista cerrada de delitos, sino a un núcleo más o menos amplio de los mismos. (pp. 329-330)

Se pone de manifiesto la necesidad de señalar la distinción entre el sujeto activo de la conducta y quien conduce o realiza la autoría de la misma, siendo necesario para ello, como ya se ha indicado, reconocer el aspecto contextual en el cual se desarrolla el delito, si bien es cierto el delito de lavado de activos se reconoce como delito autónomo, también lo es que conforme a lo señalado por la Honorable Corte Suprema de Justicia de Colombia, en sentencia del 28 de noviembre de 2007, Magistrado Ponente ALFREDO GOMEZ QUINTERO, señala: “...el lavado de activos tal como el género de conductas a las que se refiere el artículo 323, es comportamiento autónomo y su imputación no depende de la demostración, mediante declaración judicial en firme, sino de la mera inferencia judicial al interior del proceso, en sede de imputación, en sede de acusación o en sede de juzgamiento que fundamente la existencia de las conductas punibles tenidas como referente en el tipo de lavado de activos...es claro entonces que para sentenciar por lavado de activos no se requiere de una decisión judicial que involucre al procesado en la comisión del comportamiento subyacente (delito base), entre otras razones porque el delito base puede ser cometido por terceros...", es decir el delito subyacente, actúa simplemente como ingrediente normativo, no es requisito que el mismo haya sido ejecutado por el imputado de lavado.

Paradójicamente, estas dificultades aumentan a medida que las hipótesis de reconversión son de mayor envergadura, esto es, en 
aquellos casos en los que la necesidad de pena se hace más palpable. Como es natural, el conocimiento del delito previo será más fácil de demostrar a medida que el blanqueador esté más próximo al sujeto o incluso sea el mismo- que obtuvo antes los bienes. Sin embargo, la dificultad de la prueba del elemento cognoscitivo se incrementará según aumente el grado de complejidad de la estructura criminal $y$, con ello, el volumen de riqueza sucia manejada." (pp. 330).

La penalización del delito de lavado de activos se propone entonces, casi que como figura accesoria frente a delitos más graves que se puedan dar en el orden socio-económico. Aunque no se cuestiona que el delito de lavado de activos es y debe ser un delito autónomo, sí hay que validar con detenimiento el panorama de configuración del delito, puesto que las redes criminales, al poner en uso instrumentos humanos para el movimiento de sus capitales ilegales, están poniendo en riesgo capitales, mas no la estructura misma de la organización, lo que deriva en que aun cuando haya severidad para el castigo del lavado de activos, esto poco importa a los altos mandos de la estructura delictiva.

Hay que revisar en la configuración del delito la tipología por la cual se lleva a cabo la acción delictiva para analizar el contexto socioeconómico en el que se produce el delito; el pitufeo, las transferencias y el uso de correos humanos, bien pueden obedecer a formas en las cuales el sujeto activo de la conducta desconoce la procedencia de los capitales, razón que se debe estimar para hablar más que de autoría o coautoría, en el modo de participación: 
"Así pues, si ya desde el punto de vista sustantivo no parece sostenible la penalización del blanqueo de los bienes derivados de uno o de varios delitos determinados, o de una categoría más o menos amplia de los mismos, valorada la cuestión desde el plano probatorio en relación con la vertiente subjetiva del tipo, se muestra necesario extender la delimitación del objeto material a la generalidad de delitos recogidos por las leyes penales del país. De este modo, para que una conducta de blanqueo sea dolosa -amén de conocer y querer el resto de elementos que integran el tipo objetivo-, creemos que debe bastar con que se pruebe que, al tiempo de realizar la operación, el sujeto tuvo noticia de que los bienes implicados en la misma procedían de la comisión de alguna clase de delito, con independencia de cuál fuese su naturaleza." (Fabián, 1998: pp. 330).

Resulta nuevamente dispendioso generar una diferencia entre el determinador y el autor de la misma, para efectos de valorar las condiciones de penalización que se debe dar para cada uno de los casos, llegando al punto de valorar la ausencia de responsabilidad, como se dispone en el artículo 20 del Código Penal español, que en función del caso del lavado de activos, requiere del estudio sobre el conocimiento de la comisión del delito previo por el cual se lleva a cabo la acción delictiva que da origen a los fondos.

En este sentido se debe afirmar, que para efectos no sólo de judicializar la conducta antijurídica del blanqueo de capitales, sino las conductas antijurídicas 
subyacentes, bien se puede plantear la necesidad de clarificar el reconocimiento de la autoría, la coautoría y la participación, siendo en este último ámbito, de especial análisis la complicidad, como condición novedosa que, se sugiere implementar en la caracterización de la conducta punible de lavado de activos, para el caso del sistema penal colombiano.

La complicidad como acto de contribución dolosa en la realización del hecho típico antijurídico, implica que esta cooperación sea distinta a la descrita en el tipo penal, sin embargo, considerando la complejidad en la materialización de delitos penales económicos como ocurre en el caso del delito de lavado de activos, se encuentra que bien se puede estudiar la tipificación de la conducta más allá de lo consignado en el tipo penal, revisando el marco contextual donde se desarrolla la misma para evidenciar sí en efecto, quien actúa como autor directo, es autor en los términos que plantea la teoría del dominio del hecho.

De considerar esta posibilidad, el análisis de la conducta punible desde la estructura objetiva del tipo, no debería tan sólo en determinar los elementos objetivos que lo componen, sino reparar en que quien se codifica como autor, no siempre actúa en dominio del hecho, siendo este el punto de partida para caracterizar la fase subjetiva propia de tipo doloso, en la que, aunque el autor directo, sea quien desarrolle el hecho reprochable jurídicamente, la falta del dominio del hecho, debe llevar a que se degrade su responsabilidad en la ejecución del delito de autor, a partícipe. 


\section{Análisis jurisprudencial}

Desarrollado el delito de lavado de activos, es pertinente entrar en un minucioso análisis jurisprudencial, que nos ilustre la razón por la cual, la participación en el delito de lavado de activos no se da, partiendo inicialmente, por exponer la posición generalizada en la que se halla la Corte Suprema de Justicia, respecto al delito de lavado de activos. Lo anterior, busca ser evidente en la revisión jurisprudencial, que coloca en la discusión, casos puntuales donde se ha imputado el delito, y desde allí se formulan puntos de debate sobre la posición y jurisprudencia que al respecto se ha decantado.

En atención de lo anterior, se debe indicar que la jurisprudencia que a continuación se expone, es en su integridad emitida por la Corte Suprema de Justicia en su Sala de Casación Penal - en adelante CSJ-SP -, Tribunal de cierre para la mayoría de casos asociados a este tipo delictivo, reconociendo en sus decisiones; jurisprudencia relevante para el tema analizado en este documento.

Con el propósito de lograr una mejor lógica expositiva, lo primero que sigue es analizar la línea seguida por la Corte respecto al delito de lavado de activos, para luego proceder en lo referente a la imputación del delito al sujeto, en calidad de autor o coautor y del cual se va a desprender un tercer ejercicio que corresponde a determinar que pueden existir casos en los que más que establecerse la coautoría, 
se podría establecer la participación, lo que cambiaría de lleno, las calidades imputadas al procesado.

En lo relacionado con la caracterización jurídica del delito de lavado de activos, inicialmente se debe afirmar que es reiterada la jurisprudencia de la CSJSP, respecto a la figura de delito autónomo que adquiere la actividad de lavado de activos, que como ya se ha indicado en apartes anteriores de la actual investigación, no condiciona la comprobación del delito previo para formular así la acción penal en los casos que se determine la conducta, siendo esta una posición que a su vez ha sido manifestada por este Tribunal en varias de sus sentencias, como lo es la Sentencia 27144 de 2011, en la que indica:

[I] jurisprudencia de la Sala ha sido clara en sostener que el delito de lavado de activos es de carácter autónomo; de ahí que para la acreditación que los bienes objeto del mismo proviene de algunas de las actividades ilícitas a que se refiere el artículo 323, no es necesario la existencia de una sentencia previa, sino que en el trámite debe estar patente esa situación, ya sea atribuida a quien se investiga o a un tercero (Sic).

Como consecuencia de ello, este Alto Tribunal ha establecido que la conducta se establece conforme a los verbos rectores y conductas tipificadas en el artículo 323 del Código Penal, que como ya se ha indicado, ha sido objeto de varias reformas por parte del Legislador, en procura de involucrar la gran mayoría de situaciones identificadas en la comisión de este delito, de allí que en esta misma 
sentencia, y desarrollando la posición sostenida como línea jurisprudencial por este Tribunal, la Corte remita a revisar la posición que ha adoptado en este sentido por distintas sentencias, que como claro ejemplo deja la Sentencia 28.300 de 2009 por la que sostuvo que:

En el auto del 27 de octubre de 2004 (Radicado 22.673), la Corte precisó que el lavado de activos, o blanqueo de capitales como también se le denomina, consiste en la operación realizada por el sujeto agente para ocultar dineros de origen ilegal en moneda nacional o extranjera y su posterior vinculación a la economía, haciéndolos aparecer como legítimos.

Lo anterior significa, (...) que dicha conducta típica puede ser realizada por cualesquier (Sic) persona a través de uno cualquiera de los verbos rectores relacionados en la norma -adquirir, resguardar, invertir, transportar, transformar, custodiar, administrar- bienes provenientes de los delitos de extorsión, enriquecimiento ilícito, secuestro extorsivo, rebelión, o relacionados con el tráfico de drogas tóxicas, estupefacientes o sustancias sicotrópicas, así como también del tráfico de armas y comportamientos delictivos contra el sistema financiero, la administración pública y los vinculados con el producto de los ilícitos objeto de un concierto para delinquir -conductas estas últimas adicionadas en la nueva normatividad y que no aparecían descritas en el precepto derogado-, como también lo fueron las actividades de tráfico de migrantes y trata de personas por el Art. $8^{\circ}$ de la Ley 747 de 2002; darle apariencia de legalidad o legalizar tales bienes, ocultar o 
encubrir su verdadera naturaleza, origen ubicación o destino, movimiento o derechos sobre los mismos; o realizar cualquier otro acto para ocultar o encubrir su origen ilícito.

Sin embargo, la cuestión central que se quiere develar por este documento respecto a la posibilidad de hallar participación en la comisión del delito, debe pasar por el estudio a su vez de la autoría y la coautoría, puesto que, en materia punitiva, y para el caso del marco normativo colombiano, son las dos acepciones que más se dan a imputar para este tipo de delito, siendo esta la posición que ha seguido la misma jurisprudencia del alto Tribunal. En efecto, siguiendo en el análisis de la misma providencia citada anteriormente, se debe señalar que por esta se determina igualmente que:

El lavado de activos, tal como el género de conductas a las que se refiere el artículo 323, es comportamiento autónomo y su imputación no depende de la demostración, mediante declaración judicial en firme, sino de la mera inferencia judicial al interior del proceso, bien en sede de imputación, en sede de acusación o en sede de juzgamiento que fundamente la existencia de la(s) conducta(s) punible(s) tenidas como referente en el tipo de lavado de activos.

(...). Cuando el tenedor de los recursos ejecuta esa mera actividad (aparentar la legalidad del activo) y oculta su origen e inclina su actividad al éxito de ese engaño, orienta su conducta a legalizar la tenencia del activo, es claro que incurre en la conducta punible porque su comportamiento se concreta en dar 
a los bienes provenientes o destinados a esas actividades apariencia de legalidad; es decir, encubre la verdadera naturaleza ilícita del producto.

Por lo mismo, el Tribunal a la hora de analizar el caso concreto de la sentencia por la que la Fiscalía pide la casación de la sentencia del Tribunal Superior de San Andrés, Providencia y Santa Catalina, por la que se absolvió a los procesados, y en el entendido que el argumento del segundo Tribunal fue la falta de un acervo probatorio consistente que diera cuenta de la conexión entre los dineros incautados y la actividad ilícita de narcotráfico, la Sala de Casación determinó al respecto que:

Bajo esa lógica, en el presente caso, para tipificar el delito de lavado de activos, bastaba entonces la demostración de que el sujeto activo de la conducta ocultó o encubrió 'la verdadera naturaleza, origen, ubicación, destino, movimiento o derecho sobre tales bienes', sin necesidad de acreditar con una decisión judicial en firme el delito de donde provenían los recursos ilícitos, pues la actividad ilegal subyacente sólo requiere de una inferencia lógica que la fundamente.

(...). Se insiste: la imputación por lavado de activos es autónoma e independiente de cualquier otra conducta punible y para fundamentar la imputación y la sentencia basta que se acredite la existencia de la conducta punible subyacente a título de mera inferencia por la libertad probatoria que marca el sistema penal colombiano. 
Aquí se observa pertinente agregar que el derecho a la no autoincriminación ciertamente autoriza al procesado a asumir ciertos comportamientos procesales, pero su silencio o sus aserciones carentes de sustento, pueden objetivamente demeritar su posición si en su contra se reúnen suficientes elementos probatorios allegados por el Estado y no refutados.

La sentencia en comento de la Corte Suprema de Justicia, remite para efectos aclaratorios a la Sentencia 23.754 de 2008 de este Tribunal, por la que se sindica a una persona del delito de lavado de activos, alegando por parte de la defensa, el desconocimiento que tenía la persona acusada, del transporte de dinero bajo la figura de correo humano, frente a lo cual el Tribunal indica que esta es una conducta susceptible de ser analizada por la regla de experiencia, frente a la que el Tribunal aclara:

En el presente caso, los juzgadores se valieron de prueba indirecta para deducir que el dinero transportado (...) tenía su origen en una actividad ilícita. Fue así como partiendo de un hecho indicador debidamente probado, a saber las propias explicaciones de la procesada en torno a la forma como recibió la encomienda de traer desde España las películas fotográficas de manos de un completo extraño, como el señalado Narciso Romero, pues apenas lo había conocido en el lobby de un hotel, encargo al que accedió a pesar de que como auxiliar de vuelo de la aerolínea Avianca había recibido suficiente instrucción para detectar situaciones irregulares en esa clase de encomiendas, las cuales por demás tenía prohibido recibir, circunstancia a la 
que se agregó la actitud temerosa que asumió una vez fueron descubiertos los rollos fotográficos en su equipaje, datos que aunados a la omisión de declarar el dinero ante las autoridades aeroportuarias, le permitieron al juzgador deducir que la procesada sabía de la ilícita procedencia del capital.

Para los jueces de instancia los hechos indicadores apuntaban al conocimiento que tenía (...) sobre el origen delictivo de las divisas que portaba, dejando entrever una regla de la experiencia según la cual quien es consciente de la legalidad de su comportamiento no oculta su materialidad ni ofrece explicaciones ayunas de verdad, razonamiento que encuentra válido la Sala y que tampoco cuestiona el demandante.

La inferencia efectuada por el fallador en relación con el comportamiento ilícito subyacente, es, en criterio de la Sala, suficiente para acreditar la existencia de la actividad ilegal fuente del activo decomisado, independientemente de la responsabilidad que tenga o no la procesada en el delito de enriquecimiento ilícito de particulares, pues como lo advierte el Delegado en su concepto, la forma en que la misma llevaba camuflada la representativa cantidad de US $\$ 107.200$ en unos elementos en apariencia inocuos, es indicativa de que al menos alguien ya había obtenido un enriquecimiento ilícito, ya que el manejo subrepticio de esos montos en efectivo no suele corresponder al de personas dedicadas a negocios lícitos. 
Por lo tanto, el juzgador no incurrió en el falso juicio de existencia por suposición que le achaca el defensor, ya que la inferencia del origen ilícito de la divisa incautada, provino de la apreciación de los elementos materiales probatorios incorporados al proceso".

Si bien el anterior caso refleja en el autor de la conducta una condición de conocimiento y exposición frente a las implicaciones que conllevaba la realización del ilícito, es procedente para el mismo seguir la tesis de la corporación por la que se procede a declarar la comisión en calidad de autor, del delito de lavado de activos, a quien se sindica por este delito para el particular caso, desarticulando la tesis seguida por el Tribunal de segunda instancia, que lleva en mérito de la aplicabilidad de la regla de la experiencia, a allanar el camino de una ausencia de responsabilidad:

No puede pasar por alto la Sala que para fundamentar la absolución de (...), el juzgador construyó, además, una presunta regla de la experiencia según la cual, por lo general, quienes sirven de correos para el transporte de las divisas son usados por terceros como instrumentos para su ingreso al país y posterior incorporación al torrente económico, por lo que los ejecutores del transporte no son los dueños de las mismas.

No obstante, en criterio de la Sala esa máxima carece de las notas características de generalidad y universalidad, consustanciales a las reglas de la experiencia. 
Para puntualizar en este argumento, la CSJ-SP se apoya en jurisprudencia del mismo Tribunal, como es la Sentencia 23.593 del 11 de abril de 2007, por la que la Corte define respecto a la regla de la experiencia que, si un fenómeno es repetitivo en circunstancias similares, supone la realización de pronósticos en la suposición de los efectos de las conductas, entendiendo así un fenómeno causal, que, para efectos de la actual investigación, hace parte de la valoración socio-jurídica de la configuración delictiva para determinar la participación, aunque antes de ahondar en ello bien se debe generar la siguiente claridad sobre la regla de la experiencia, en expresión de la Corte:

Sobre la aducida violación de las reglas de la experiencia, también con apoyo en los juiciosos argumentos de la Delegada, podemos afirmar, como invariablemente lo ha sostenido la jurisprudencia de la Sala, que estas reposan en la reiterada y amplia manifestación fenoménica de un hecho o actuación, apreciado y catalogado como tal y pasible de asumir de nuevo configurado, dentro de similares condiciones temporo-espaciales, hasta devenir insoslayable su pretensión de universalidad, siempre y cuando no se ofrezca una condición excepcional que faculte significar otra respuesta, distinta de la que se espera.

Así las cosas, como lo ha dicho la Corte, en pertinente cita de la Delegada, las reglas de la experiencia corresponden al postulado "siempre o casi siempre que se presenta $A$, entonces sucede $B "$ ", motivo por el cual es posible efectuar pronósticos, -referidos a predecir el acontecer que sobrevendrá a la 
ocurrencia de una causa especifica (prospección)-, y diagnósticos, predicables de la posibilidad de establecer a partir de la observación de un suceso final su causa eficiente (retrospección)-.

En consideración de la Corte el fenómeno repetitivo de una acción lleva a la deducción en la existencia de unos condicionantes causales, para el caso, se presume que en un delito como el de lavado de activos, para una persona que trabaja en un medio en el que se dan en mayor medida los casos de correos humanos, es por lo menos lógico que sospeche de quien le indique que transporte una mercancía en la manera que le fue indicada, por lo que desestima el tribunal el argumento dado por la defensa respecto al desconocimiento de lo transportado.

Aun cuando la persona imputada desconozca que es dinero, o se trataba de otro elemento que connote la comisión de un delito, se desestima que obrara con desconocimiento total y por ende insospechadamente, razón por la cual no se puede dar otro tipo de imputación, que la de autoría en el delito de lavado de activos. Sin embargo, existen hechos que posiblemente sí pueden conducir a la actuación de forma insospechada, o por lo menos, que es el punto central que se intenta develar por este documento, con una reverencia derivada de la subordinación que deja la relación social del contrato de trabajo, que puede estar conjugado con un temor reverencial, que deja la necesidad de tener una fuente de ingreso, que al no ser una categoría comúnmente aceptada para el sistema penal colombiano, merece especial desarrollo en lo que sigue en los siguientes párrafos. 
Por Sentencia 42.722 de 2014, la Sala de Casación Penal buscaba resolver la casación interpuesta por la delegada de la Fiscalía General de la Nación, quien en proceso adelantado frente a quien se sindica del delito de lavado de activos, se encontró inconforme con la determinación del Tribunal Superior de Medellín quien en 2013 absolvió de los cargos imputados a quien actúa como autor de los hechos consignados en la Sentencia, sobre transacciones comerciales fraudulentas:

La Unidad Administrativa Especial de Información y Análisis Financiero UIAF, durante el período comprendido entre los meses de diciembre de 2002 y junio de 2003, elaboró el registro de operaciones sospechosas de diferentes empresas por el manejo de dinero producto del tráfico de estupefacientes en el exterior, para lo cual la empresa (...), creada para brindar asesoría contable, les elaboraba falsos registros que soportaban transacciones realizadas desde las ciudades de Barranquilla, Bogotá y Medellín.

(...). Esta empresa, además de contar con otros objetos sociales en el certificado de existencia y representación legal, decía dedicarse a la actividad ganadera y las dos, habían sido creadas sin contar con los soportes legales necesarios.

Por sus cuentas bancarias circularon más de $\$ 5.000$ ’000.000 sin respaldo en actividad económica determinada. (La sindicada) fue contratada para laborar como secretaria (...), luego se desempeñó como secretaria de las dos empresas y por solicitud de su empleador y gerente, el 11 de octubre de 
2002, abrió a su nombre una cuenta corriente (...), a través de la cual se realizaron transacciones por un valor total de $\$ 128.932 .776$. La cuenta del Banco Superior, también de la procesada, manejó dineros por un valor de $\$ 23.000 .000$.

De la misma manera, sin corresponderle a su rol funcional, le expidió a varios empleados certificaciones laborales de cargo desempeñado e ingresos; y a otras personas ajenas a la empresa sobre actividades comerciales, las que no correspondían con la realidad, documentos que fueron usados para abrir cuentas bancarias utilizadas (...) para el movimiento de dineros; además, cobró cheques por ventanilla bajo la modalidad de endoso por un valor de $\$ 40.000 .000 ;$ y suplantó al contador en la firma de estados financieros que no reflejaban la verdadera situación de la empresa, circunstancias que Ilevaron a que se le formularan cargos como coautora del lavado de activos.

La CSP-SP en el análisis de las consideraciones que al respecto da la Fiscalía para casar el fallo, remite en una primera parte de sus consideraciones a hacer un repaso sobre lo dispuesto respecto al delito de lavado de activos como conducta tipificada en el artículo 323 del Código Penal, y cuyas consideraciones jurisprudenciales ya se han hecho a lo largo de este acápite, no obstante, manifiesta la Corte respecto a este punible que; "por su misma naturaleza, requiere de un número plural de personas, pues se desarrolla mediante el ejercicio de una gran variedad de operaciones encaminadas a esconder $u$ ocultar el origen espurio de dinero". 
Este sería el punto central para que un juez en un primer nivel condenara a quien opera como procesado en la coautoría del delito de lavado de activos, no obstante, en la impugnación por parte de la defensa del fallo, el Tribunal de segunda instancia determinó que no había un elemento subjetivo de dolo en quien se acusaba, puesto que reconoce la ausencia de conocimiento de la actividad ilícita, por lo que decidió absolver. Para efectos de la tesis que se sigue en este documento, resulta determinante repasar varios de los argumentos expuestos por el tribunal de segunda instancia, puesto, que a su vez que son controvertidos por la CSJ-SP, sirven para en una parte final llegar a un punto medio en el grado de partícipe, que es lo que se quiere sostener.

En esta materia, indica la Corte que; "bajo ese enfoque temático -ausencia de conocimiento de la actividad ilícita-", el Tribunal en segunda instancia absolvió a quien como parte se sindica, puesto que encontró que varias de las operaciones fueron realizadas en cumplimiento de lo que podría haber determinado quien se implica como cotidianas en el marco de la relación laboral que tenía, que aunque todas debieron verse con sospecha, no existía experiencia, y conocimiento por parte de quien se sindica, para que actuara de otra manera. Explica la Corte respecto a lo anterior que:

A partir de este panorama fáctico, el Tribunal elaboró juicios de valor, desde los cuales dijo, existían dudas sobre el conocimiento y la voluntad de la acusada para concurrir en la comisión del delito de lavado de activos, los cuales ahora, se muestran equivocados por desconocer los parámetros de la 
sana crítica, reflexiones que la Corte pasa a verificar en camino de demostrar su desacierto.

Así, se dice en el fallo, que de la experiencia de (...) no se infiere conocimiento ni experiencia "superlativa", que le demandara un deber adicional de cuidado, pues su calidad de secretaria le significaba cumplir órdenes y facilitar gestiones del día a día, sin que se esté en presencia de alguien que en la organización laboral hubiere sido contratada para ejercer actividades de dirección y manejo en ventas, relaciones comerciales o administración, sin que la fuerza de costumbre la llevara a ser codirectora de lo que sucedía en la empresa, como de forma equivocada lo declaró el juez de primer grado.

Se trataba de una sociedad simple, en la que se distinguían las funciones de dirección y ejecución, ejercidos por el gerente y el contador, quienes aceptaron los cargos por lavado de activos y fueron condenados. De otro lado estaban la secretaria y los mensajeros, división que se conservó, en donde el jefe imponía lo que se debía hacer acorde con las necesidades de la operación, sin consideración al cargo que se ostentaba y sin suministrar información o explicaciones del porqué de los actos que los empleados adelantaban a nombre propio.

Según el Tribunal la apertura de cuentas y sus movimientos no tienen una relación directa con el lavado de activos, pues de ahí no se desprende el 
conocimiento de toda su trama criminal, porque eran precedidos por órdenes de trabajo que le dieron y que la acusada cumplió fielmente, hecho que puede ser objeto de crítica, “...pero en una relación laboral de subordinación, pudo haber actuado, no por la representación de una extrema ilicitud como la que se le adjudica, sino por la necesidad de conservar el trabajo o anteponer $\underline{\text { necesidades económicas, de los que se puede desprender su acuciosidad }}$ extrema de satisfacer a su jefe." (Subrayado del autor).

El subrayado que corresponde a una citación que hace la CSJ-SP, respecto a la sentencia de segunda instancia que emite el tribunal de impugnación, siendo este un elemento que en cuanto a la tesis desarrollada en este documento, se debe tener en cuenta como elemento para formular la modalidad en el cargo imputado, puesto que existen unas condiciones socio-jurídicas que deben ser analizadas a la hora de imputar cargos frente a delitos de tipo económico, de allí que en situaciones como esta, se tiende a presentar lo que en segunda instancia se establece respecto al hecho jurídico analizado, reproduce la Corte en el análisis un argumento usado en el tribunal de segunda instancia por el que se manifiesta que: "al no atribuírsele a la acusada el haber obtenido ganancias personales con las actividades realizadas, su actuar no es consonante con la participación delictiva en los hechos que se juzgan".

Sin embargo, el Tribunal a la hora de justificar su ratio decidendi, acude al precepto de la regla de la experiencia para determinar que en un obrar lógico, el sindicado, debe tener un mínimo valorativo de las conductas que realiza, para con 
esto presumir lo que está o no, ajustado a la ley, indicando al respecto el Alto Tribunal que, esta es una condición con pretensión de universalidad y generalidad, en tanto, la excepción a la misma, conduce precisamente a que esta no sea entendida en dichas condiciones:

Ha sido reiterada la jurisprudencia de esta Corporación al definir la regla de la experiencia, como una construcción teórica relacionada con la costumbre, la cultura y el diario transcurrir de las personas en comunidad, dentro de un contexto específico, las cuales tienen características de generalidad o universalidad y que normalmente son utilizadas por los jueces en la elaboración de los juicios de valor al momento de apreciar los medios de prueba, planteadas a partir de hechos o circunstancias debidamente acreditados (CSJ SP, 21 nov. 2002, rad. 16472; 25 ago. 2004, rad. 21829; 20 nov. 2011, rad. 36544; 2 mar. 2011, rad. 35621, entre otras).

Que son enunciadas bajo la fórmula lógica "siempre o casi siempre que ocurre $A$, entonces sucede $B$ ". No debe existir excepción a la regla, porque de ese modo pierde la condición de universalidad.

Este evento hipotético no se cumple en este caso, pues como se declaró probado, (sindicado) no se limitó simplemente a cumplir con las tareas propias de una secretaria que asume con obediencia las órdenes impartidas por su jefe, bajo el temor reverencial de perder su empleo, pues las 
actividades ilegales que se le reprochan las realizó, inclusive, durante varios meses después de desvincularse de (la empresa).

Igualmente, la premisa no refleja universalidad, porque no es cierto que las personas en condiciones generales, estén dispuestas incluso a incurrir en actividades ilícitas para conservar su trabajo. La práctica común enseña lo contrario, que cuando las actividades laborales se alejan del dictado de la moral y las buenas costumbres o implican un exceso o extralimitación, como lo acota la fiscal recurrente, es frecuente que los empleados decidan abandonar sus puestos de trabajo mediante la renuncia, porque a cambio del ingreso del salario, no exponen ni afectan su dignidad e integridad moral; tampoco asumen delinquir con la implicación de ser procesados judicialmente por la comisión de un delito.

En el siguiente desarrollo expositivo del argumento del Alto Tribunal, entra en juego un elemento no puesto en consideración hasta ahora, con relación a que quien se sindica, aún después de haber salido de la compañía, siguió adelantando actividades relacionadas con el lavado de activos, por lo que la Corte desestima el argumento del tribunal en segunda instancia respecto al temor reverencial al que acude quien se sindica, en su condición subordinada, y necesidad de seguir manteniendo un empleo, como propósito para el logro de un ingreso.

No obstante, no se puede desconocer que dichas actividades, hayan seguido existiendo en cumplimiento de un tipo de intimidación o elemento persuasivo que 
no fuese propiamente una retribución económica, dado que, por la misma sentencia del tribunal superior, no alcanza a reconocer en evidencia, la existencia de algún tipo de contraprestación económica o material por la acción de las conductas sindicadas, elemento que a saber, para el Tribunal no se debe dar para la configuración del delito de lavado de activos, desvirtuando lo proferido en segunda instancia.

Por los distintos argumentos antes expuestos para este caso, el tribunal casa el fallo impugnado dejando en firme la sentencia de primera instancia por la que se condena a quien se sindica, por el delito de lavado de activos en calidad de coautora, del mismo, ahora bien, a partir de ello, conviene determinar si en efecto, se puede atribuir esa calidad o la de partícipe. Para desarrollar este argumento, se debe recordar que como se establecía en capítulos anteriores, la calidad de cómplice, recae principalmente en el hecho que el sujeto partícipe, sea importante para la configuración del delito, pero no necesario, y en tal sentido los dos casos expuestos sirven para dejarlo así claro.

En el primer caso, con relación al delito cometido por la modalidad de correo humano, se infiere como en el mismo análisis de la sentencia se hace, que la persona que sirvió como correo humano es importante para que el dinero llegue al lugar al que se le quería dar destino, pero bien se puede deducir, que el autor, en el pleno conocimiento de la organización criminal a la que debe pertenecer, claramente sabría que si no es a través de esa persona puede ser a través de otra, siendo en suma, una pieza cambiable en el andamiaje y final configuración de este 
delito. Sucede igual en el segundo caso; aunque no se especificó en lo expuesto, a quien se le diera uso para prestar su nombre en función de introducir al sistema financiero unos dineros, actuaba en la misma condición de quien como compañeros de trabajo eran mensajeros, es decir, quien es sindicado, no era pieza irremplazable en la estructura delictiva por la que se lavó dinero.

La anterior consideración, se plantea como uno de los elementos a tener en cuenta en la configuración de la complicidad, siguiendo la tesis que sugiere que en el delito de lavado de activos se admite la complicidad como una forma de participación, esto teniendo en cuenta que dar solo la característica de parte reemplazable en el andamiaje de una estructura delictiva, para con ello establecer la complicidad, puede también abrir un boquete irresoluble para este y otros delitos asociados a las redes delincuenciales trasnacionales.

No obstante y frente a lo planteado, la más reciente jurisprudencia dictada por la CSJ-SP, señala la posibilidad de poder degradar la participación a partir de la suscripción de preacuerdos a los cuales se acojan los sindicados, ello con ocasión de lo dictado en la Ley 1453 de 2011, que modificó el artículo 68A del Código Penal, en el parágrafo que hace una excepción a la exclusión de beneficios y subrogados penales, y que a su vez fue modificado por la Ley1474 de 2011, al respecto de la celebración de preacuerdos en este tipo de delito, el Alto Tribunal señala;

Es cierto que en los preacuerdos los delegados de la Fiscalía General de la Nación están inhabilitados para crear tipos penales y para 
calificar jurídicamente los hechos de manera contraria a la ley penal preexistente, dado el condicionamiento impuesto por la Corte Constitucional en sentencia C-1260/05, pero sí están facultados para que, en aras de sacar avante las negociaciones, adecuen la conducta en una descripción típica relacionada, que comporte una pena menor, siempre que las circunstancias fácticas no sean alteradas. (Corte Suprema de Justicia, Sala de Casación Penal, Sentencia 45.736 de 2016)

En este sentido, se genera una proximidad frente a la situación hipotética planteada en el transcurso del documento, a saber, la de poder establecer la modalidad de participación en calidad de cómplice, en situaciones sobre las cuales se evidencia una participación inducida por el claro conocimiento de la procedencia de los dineros destinados al lavado de activos, o también, cuando se actúe por un temor reverencial hacia el determinador de la conducta. Para ver la procedencia de lo señalado, bien se puede volver a la jurisprudencia citada, que a su vez se remite a su propia jurisprudencia, en este caso, la Sentencia 41.570 de 2013 , en la que frente a los preacuerdos genera esta amplia caracterización:

En lo atinente a cuáles aspectos consideró el legislador son susceptibles de ser preacordados, encontramos que en el artículo 348 de la Ley 906 de 2004 se consagró de manera escueta que se trata de convenir lo que "implique la terminación del proceso"; mientras en los artículos 350, 351 y 352 del mismo compendio normativo se 
concreta el objeto que compromete esa finalización judicial, al establecerse que serán "los hechos imputados y sus consecuencias" sobre los que recaerán los preacuerdos y las negociaciones, lo cual implica la admisibilidad por parte del imputado o acusado en forma libre, consciente, espontánea y voluntaria de situaciones que cuenten con un mínimo de respaldo probatorio.

Respecto de este tópico la Corte pacíficamente ha considerado que deben ser objeto de convenio, habida consideración de los elementos de prueba y evidencias recaudadas:

"el grado de participación, la lesión no justificada a un bien jurídico tutelado, una específica modalidad delictiva respecto de la conducta ejecutada, su forma de culpabilidad y las situaciones que para el caso den lugar a una pena menor, la sanción a imponer, los excesos en las causales de ausencia de responsabilidad a que se refieren los numerales 3, 4, 5, 6 y 7 del artículo 32 del C.P, los errores a que se refieren los numerales 10 y 12 de la citada disposición, las circunstancias de marginalidad, ignorancia o pobreza extremas (artículo 56), la ira o intenso dolor (artículo 57), la comunicabilidad de circunstancias (artículo 62), la eliminación de casuales genéricas o específicas de agravación y conductas posdelictuales con incidencia en los extremos punitivos, pues todas estas situaciones conllevan circunstancias de modo, tiempo y lugar que demarcan los hechos por 
los cuales se atribuye jurídicamente responsabilidad penal y por ende fijan para el procesado la imputación fáctica y jurídica."

Recogiendo el planteamiento de la CSP-SP, se establece que en efecto para una conducta delictual como el lavado de activos es ostensible la posibilidad de degradar la participación en condiciones específicas, que, a partir de la lectura de lo dispuesto por el Alto Tribunal, puede ser en los casos previamente mencionados del desconocimiento espurio del origen de los fondos, o las acciones adelantadas por lo que se ha señalado como temor reverencial, acudiendo a las materias que ha señalado el Alto Tribunal, se pueden negociar en los preacuerdos. En la misma Sentencia 41.570 de 2013, la Corte señala;

"Estas negociaciones entre la fiscalía e imputado o acusado no se refieren únicamente a la cantidad de pena imponible sino, como lo prevé el inciso $2^{\circ}$ del artículo 351, a los hechos imputados y sus consecuencias, preacuerdos que «obligan al juez de conocimiento, salvo que ellos desconozcan o quebranten las garantías fundamentales».

Que la negociación pueda extenderse a las consecuencias de la conducta punible imputada, claramente diferenciadas de las relativas propiamente a la pena porque a ellas se refiere el inciso $1^{\circ} \mathrm{del}$ mismo artículo, significa que también se podrá preacordar sobre la ejecución 
de la pena (prisión domiciliaria o suspensión condicional) y sobre las reparaciones a la víctima".

Lo planteado, conduce a valorar positivamente para efectos de brindar celeridad a la justicia, sin violar el principio de legalidad, que la Fiscalía adelante este tipo de negociaciones, aunque, en el parecer de la CSJ-SP, esto ha llevado a que los preacuerdos adquieran un valor amplio en términos de la imputación y lectura punitiva de todo tipo de delito, entre los cuales se incluye el lavado de activos. Recogiendo la posición de la Corte frente a este punto mencionado, se vuelve a la Sentencia 41.570 de 2013, por la que el Alto Tribunal genera el siguiente corolario frente a la institución de los preacuerdos:

Evidente es, entonces, la profunda transformación que se ha producido en el ordenamiento jurídico con la adopción de la institución de los preacuerdos y negociaciones, la cual genera como consecuencia obvia que el acuerdo pueda incidir en los elementos compositivos o estructurales del delito, en los fenómenos amplificadores del tipo, en las circunstancias específicas o genéricas de agravación, en el reconocimiento de atenuantes, la aceptación como autor o como partícipe (cómplice), el carácter subjetivo de la imputación (dolo, culpa, preterintención), penas principales y penas accesorias, ejecución de la pena, suspensión de ésta, privación preventiva de la libertad, la reclusión domiciliaria, la reparación de 
perjuicios morales o sicológicos o patrimoniales, el mayor o menor grado de la lesión del bien jurídicamente tutelado.

(...). Ello es así, en razón a que uno de los objetivos perseguidos por el legislador con el nuevo sistema procesal, sin descuidar el respeto absoluto por la defensa y el debido proceso, fue el de procurar otorgar celeridad al proceso mediante la confluencia de voluntades y el consenso en la solución del conflicto, que obedece a los fines esenciales del Estado social de derecho de facilitar la participación de todos en las decisiones que los afectan, según el artículo $2^{\circ}$ de la Constitución Política.

Con esta apreciación, se llega a valorar positivamente para efectos de considerar la aplicabilidad de la degradación de la pena en un delito como el lavado de activos, la figura de los preacuerdos, que, en principio, se puede establecer como ruta que lleve a considerar la degradación de la partición en la comisión delictiva del mencionado, condición que bien se puede desarrollar, de la mano de la lectura socio-jurídica en la configuración del delito, como sucede en los casos de los correos humanos, transferencias fraccionadas de dineros ilícitos, o la ya mencionada modalidad de pitufeo.

Ahora bien, de acuerdo con el Artículo 348. - Finalidades. Capítulo Único, del Título II Preacuerdo y negociaciones entre la fiscalía y el imputado o acusado del C.P.P. los preacuerdos, tienen como fin humanizar la actuación procesal, 
obtener una pronta y cumplida justicia, activar la solución de los conflictos sociales que genera el delito, propiciar la reparación integral de los perjuicios ocasionados con el injusto y lograr la participación del imputado en la definición de su caso.

De conformidad con el artículo 350. - Preacuerdos desde la audiencia de formulación de imputación. El preacuerdo es válido, desde la formulación de la imputación y hasta antes de ser presentado el escrito de acusación, en que Fiscalía e imputado podrán llegar a un consenso sobre los términos de la imputación.

De lo anterior se establece que el imputado se declarará culpable del delito o de uno relacionado de pena menor, a cambio de que el Fiscal:

1.- Elimine de su acusación alguna causal de agravación punitiva, o algún cargo especifico.

2.- Tipifique la conducta, dentro de su alegación conclusiva, de una forma específica con miras a disminuir la pena.

Así mismo el Artículo 351. - Modalidades. Inciso 2 señala: también podrán el Fiscal y el imputado llegar a un preacuerdo sobre los hechos imputados y sus consecuencias. Si hubiere un cambio favorable para el imputado con relación a la pena por imponer, esto constituirá la única rebaja compensatoria por el acuerdo.

El anterior texto se convierte en una, de varias modalidades legales para resolver el conflicto penal en el que se encuentran inmersos los ciudadanos implicados, por lo que la Fiscalía en acuerdo con los imputados asesorados por su 
defensa técnica pueden seleccionar la fórmula que más ventaja obtenga a los intereses de cada parte, de acuerdo a los fines y objetivos dentro de la acción penal.

La directiva 001 del 28 de Septiembre de 2006, impartida por el señor Fiscal General de la Nación, fijó directrices para la celebración de preacuerdos y negociaciones entre la Fiscalía y el imputado o acusado, indicando que se perseguía con la celebración de los mismos y concretando su finalidad, que no es otra, que servir de instrumentos jurídicos al ente acusador para hacer justicia material y efectiva, a través de la participación activa del Fiscal y el imputado o acusado, además de las razonables consideraciones de los intereses de éste y de la víctima. Precisando que no podrán tener como único objetivo el resolver casos, acelerar la justicia, descongestionar los despachos judiciales, ni servir simplemente de medio de conciliación o mediación.

Acorde con lo anterior y en especial lo dispuesto en el artículo 3 de la citada directiva, que señala respecto de los acuerdos frente a los términos de la imputación: "... En este caso el preacuerdo debe versar sobre la tipificación de la conducta con todas las circunstancias que la rodean en plurales aspectos como: eliminación de agravantes, reconocimiento de atenuantes, grado de participación y la forma de imputación subjetiva (...) se puede acordar formas más benignas de intervención en la conducta punible que impliquen rebajas punitivas siempre y cuando no se varié la denominación del delito en que se participa...", aspecto este último sobre el cual versará el presente preacuerdo. 
La Corte Suprema de Justicia en sala penal dentro del radicado 34.829 del 27 de abril de 2011, con ponencia del Dr. Barceló, resolviendo un recurso en segunda instancia abordó el tema de las situaciones que podrían ser objeto de un preacuerdo, relacionando una docena de situaciones.

Aspecto reiterado de conformidad con la ya cita Sentencia de segunda instancia No. 41.570 del 20 de noviembre de 2013, con ponencia del Dr. Fernando Castro Caballero, en su texto orientador, reconoce que es factible y viable degradar la participación de autor a cómplice, si con ello se logra el allanamiento a cargos del procesado que contribuye a humanizar el proceso penal, agilizar la decisión final, generando un menor desgaste de la administración de justicia, materializándose el principio constitucional que permite a las personas participar en las decisiones que los afectan.

De conformidad con la Sentencia de casación, con radicación No. 40.871 del 16 de julio de 2014, con ponencia del Magistrado Leónidas Bustos Martínez, los preacuerdos son una forma que genera una resolución al conflicto penal de manera ágil y por la vía abreviada que permite "única forma de garantizar su operatividad".

Igualmente en sentencia 40.382 del 24 de Junio de 2015, con Ponencia del mismo Magistrado Bustos Martínez, se señala que en términos de individualización de la pena, se debe atender a una justa y ponderada del lus Puniendi, buscando una proporcionalidad que evite los excesos del lus Puniendi atendiendo los principios de necesidad, proporcionalidad y razonabilidad previstos en el artículo 3 
del C.P. Frente al incremento por los concursos de delitos el incremento punitivo, no puede corresponder a simples sumatorias de sanciones, por el contrario debe ser un aumento mermado para posibilitar las expectativas de reintegración social, manteniéndose en todo caso la retribución y la prevención especial.

Y de acuerdo con la sentencia 45.736 del 24 de febrero de 2016, aborda los temas en que se puede preacordar entre Fiscalía y Defensa, refiriéndose de manera expresa a la controversia que se había presentado en cuanto a las situaciones de flagrancia, se les podía aplicar la figura consensuada de degradación punitiva la pena de un cómplice, aspecto que fuera resuelto en el sentido de establecer que esta figura de degradación de autor a cómplice es una modalidad de preacuerdo que no riñe con lo estipulado en el artículo 301 parágrafo en el sentido de clarificar que la pena a imponer es la que corresponde a la figura de la complicidad dentro del marco punitivo que el legislador determino para esta figura con todas sus consecuencias, “...ninguna injerencia tiene el límite de rebaja por razón de la captura en flagrancia" 


\section{Conclusiones}

Puede establecerse, que el lavado de activos o blanqueo de capitales es una modalidad delictiva que surge en el ámbito de las redes nacionales y trasnacionales de crimen organizado, las cuales, en el desarrollo de sus actividades, han optado por adherir a su estructura delictiva, la acción de introducir en el circuito financiero dineros para darles apariencia de legalidad, ingresando ingentes sumas de dinero de actividades lícitas, para con esto camuflar su procedencia.

Por esto, no puede dejarse de prever una complejidad en la configuración del delito de lavado de activos, en la medida que puede identificarse su estructura tanto en el escenario transaccional virtual, como en las transacciones que se dan desde el escenario real de la economía, marcando un amplio panorama para la determinación de la punibilidad, que se traslapa a la judicialización del delito y la determinación de la existencia de concurso de personas en la conducta punible.

Ahora, teniendo en cuenta las distintas posibilidades por las cuales puede configurarse el delito de lavado de activos, se puede permitir que una persona pueda ser condenada como autor, pero igualmente a título de determinador o cómplice, en la medida que los elementos de estas formas de participación caben en este delito, dado que la responsabilidad no recae exclusivamente en el sujeto 
activo del delito, sino que para casos como el sistema penal colombiano, compromete una plurisubjetividad punitiva.

En lo que respecta a la figura del cómplice, se establece que este es un partícipe que le colabora al autor, favoreciendo la comisión de la conducta antijurídica, aumentando a su vez las posibilidades para lesionar o amenazar el bien jurídico tutelado, de tal manera que sin su colaboración, se reducen considerablemente las posibilidades de que hubiera lesión al bien jurídico tutelado, reconociendo técnicamente la existencia de cinco elementos; 1) el autor, 2) un acuerdo de voluntades previo o concomitante a la conducta del autor, 3) que el aporte del cómplice consista en una ayuda que favorezca la conducta del autor, 4) que el cómplice actúe dolosamente, y 5) que la cooperación del cómplice sea concomitante a la realización de la conducta antijurídica o posterior a ésta por acuerdo previo o concomitante a ella.

En razón de lo anterior, se establece la hipótesis que se elabora para este documento, por la que se sugiere, que para un delito como el de lavado de activos, el reconocimiento de distintos grados de punibilidad abre el espacio para declarar la complicidad como una posibilidad jurídica imputable, sin embargo, para que ello resulte, es importante indagar sobre la autoría del hecho, definiendo quien efectivamente desarrolla la conducta punible, para luego establecer la coparticipación. 
Esto ha llevado a la revisión analítica del tratamiento delictivo del lavado de activos tanto en el contexto jurídico nacional, como en lo que sucede en el exterior, encontrando por ejemplo que en el sistema penal español, se han establecido condiciones jurídicas como el miedo insuperable, que aunque no se puede asumir directamente esta modalidad como complicidad, si deja entrever la posición de análisis desarrollada en el actual documento sobre los contextos que conducen a la realización del ilícito.

La posibilidad que se establece bajo este supuesto es la de reconocer en el sujeto activo de la conducta, una exención de responsabilidad criminal en la medida que el miedo insuperable, condiciona al sujeto a la necesidad de desplegar la conducta delictiva, evitando un mal que puede considerar insuperable ante la no realización del ilícito, que se presenta como amenaza, que puede llevar al caso de la inculpabilidad en el sujeto activo de la conducta, puesto que sus riesgos latentes a los que se expone ante la no materialización de la conducta, por lo que se propone diferenciar al sujeto activo de la conducta y al autor, conduciendo a un tipo de principio de accesoriedad en la participación, en la que el sujeto activo de la conducta responde por la modalidad delictiva, aunque con una pena notablemente inferior a la del autor.

Dentro de los casos de pitufeo que se dan en el sistema penal colombiano, es común encontrar a personas que atendiendo a una orden de un superior en una organización aparentemente legal -por la que se le genera una relación laboral subordinada-, y de la cual se podría igualmente predicar un temor reverencial, 
lleven a cabo transferencias de dinero o asimismo presten sus nombres para la apertura de productos financieros por los que posteriormente se manejan grandes sumas de dinero, o funjan como representantes legales aunque en la realidad nunca ejerzan a no ser que se requiera su firma en cualquier transacción comercial facilitar la comisión del lavado de activos, y que una vez descubiertos por las autoridades, el procedimiento legal acorde a nuestro ordenamiento normativo es imputarles el delito de lavado de activos, toda vez que tales conductas conllevan al perfeccionamiento del delito en mención.

Si bien en estos casos no se pretende descartar la responsabilidad, sí se podría plantear la posibilidad tal y cómo lo ofrece el sistema español de una culpabilidad reducida, lo cual debe partir de hacer una ponderación al diferenciar la autoría de la participación bajo el grado de responsabilidad o de conocimiento con relación a la comisión del delito previo, a través del cual se obtienen los fondos, para la trasgresión de la conducta delictiva del lavado de activos. Aunque no se cuestiona que el delito de lavado de activos es y debe ser un delito autónomo, sí hay que validar con detenimiento el panorama de configuración del delito, puesto que las redes criminales, al poner en uso instrumentos humanos para el movimiento de sus capitales ilegales, están poniendo en riesgo capitales, más no la estructura misma de la organización, lo que deriva que aun cuando haya severidad para el castigo del lavado de activos, esto poco importa a los altos mandos de la estructura delictiva.

Hay que revisar en la configuración del delito la tipología por la cual se lleva a cabo la acción delictiva para analizar el contexto socioeconómico en el que se 
produce el delito; el pitufeo, las transferencias y el uso de correos humanos, bien pueden obedecer a formas en las cuales el sujeto activo de la conducta desconoce la procedencia de los capitales, razón que se debe estimar para hablar más que de autoría o coautoría, de un modo de participación.

Resulta nuevamente dispendioso detenerse en generar una diferencia entre el sujeto activo causante de la conducta y el autor de la misma para efectos de valorar la culpabilidad y condiciones de penalización que se deben dar para cada uno de los casos, en función, del conocimiento de la comisión del delito previo por el cual se lleva a cabo la acción delictiva que da origen a los fondos. En este sentido se debe afirmar, que para efectos no sólo de judicializar la conducta antijurídica del blanqueo de capitales, sino las conductas antijurídicas subyacentes, bien se puede plantear la necesidad de clarificar el reconocimiento de la autoría, la coautoría y la participación, siendo en este último ámbito, de especial análisis la complicidad.

Por lo anterior, se considera que la complicidad demanda de una contribución dolosa al hecho punible, que para delitos económicos se debe expresar en la contribución a la conducta, sin embargo, en el caso de que la persona partícipe actúe supeditado a un temor reverencial, y que en últimas se halle que la configuración de los hechos no se dieron esencialmente en una condición premeditada tendiente a la comisión del delito, se sugiere no hablar de coautoría, sino de participación delictiva en la condición de copartícipe: cómplice. 


\section{Bibliografía}

Antolinez, B. N. (2009). Lavado de activos: influencia de la globalización e internet, efectos en el sistema financiero de los países y organismos de control y vigilancia. Bogotá: Librería Ediciones del Profesional LTDA.

Archila, J. E. (2013). La prueba en el delito de lavados de activos. Bogotá: Grupo Editorial Ibáñez.

Caballero, C.; Amaya, A. (2011). La lucha contra el lavado de activos: instituciones, resultados y desincentivos. En: Gaviria, A.; Mejía, D. (compiladores). Políticas antidroga en Colombia: éxitos, fracasos y extravíos. Bogotá: Universidad de los Andes.

Cadena X.; Cárdenas, M. (2004). Las remesas en Colombia: costos de transacción y lavado de dinero. Fedesarrollo WorkingPapers, 24.

Caparrós Fabián, E. (1998). El delito de blanqueo de capitales. Madrid: Colex.

Casabianca-Zuleta, P. (2009). Algunas reflexiones sobre la complicidad y su aplicación en ciertos delitos socioeconómicos. Estudios Socio-Jurídicos, 11(1): 117-142. 
Colombia. Congreso de la República (enero 31 de 1986). [Ley 30 de 1986]. Por la cual se adopta el Estatuto Nacional de Estupefacientes y se dictan otras disposiciones. Diario Oficial: 37.335 .

Colombia. Congreso de la República (octubre 20 de 1989). [Decreto 2390 de 1989]. Por el cual se adiciona el Decreto Legislativo 1856 de 1989 y se dictan otras disposiciones tendientes al restablecimiento del orden público. Diario Oficial: 39.035.

Colombia. Congreso de la República (agosto 23 de 1993). [Ley 67 de 1993]. Por medio de la cual se aprueba la "Convención de las Naciones Unidas contra el tráfico ilícito de estupefacientes y sustancias sicotrópicas", suscrita en Viena el 20 de diciembre de 1988. Diario Oficial: 41.003.

Colombia. Congreso de la República (junio 6 de 1995). [Ley 190 de 1995]. Por la cual se dictan normas tendientes a preservar la moralidad en la Administración Pública y se fijan disposiciones con el fin de erradicar la Corrupción Administrativa. Diario Oficial: 41.878.

Colombia. Congreso de la República (febrero 21 de 1997). [Ley 365 de 1997]. Por la cual se establecen normas tendientes a combatir la delincuencia organizada y se dictan otras disposiciones. Diario Oficial: 42.987.

Colombia. Congreso de la República (julio 24 de 2000). [Ley 599 de 2000]. Por la cual se expide el Código Penal. Diario Oficial: 44.097. 
Colombia. Congreso de la República (julio 19 de 2002). [Ley 747 de 2002]. Por medio de la cual se hacen unas reformas y adiciones al Código Penal (Ley 599 de 2000), se crea el tipo penal de trata de personas y se dictan otras disposiciones. Diario Oficial: 44.872.

Colombia. Congreso de la República (enero 14 de 2003). [Ley 795 de 2003]. Por la cual se ajustan algunas normas del Estatuto Orgánico del Sistema Financiero y se dictan otras disposiciones. Diario Oficial: 45.064 .

Colombia. Congreso de la República (febrero 27 de 2006). [Ley 1017 de 2006]. Por medio de la cual se aprueba el "Convenio sobre Blanqueo, Detección, Embargo y Confiscación de los Productos de un Delito", hecho en Estrasburgo el 8 de noviembre de 1990. Diario Oficial: 46.195.

Colombia. Congreso de la República (diciembre 29 de 2006). [Ley 1121 de 2006]. Por la cual se dictan normas para la prevención, detección, investigación y sanción de la financiación del terrorismo y otras disposiciones. Diario Oficial: 46.497.

Colombia. Congreso de la República (noviembre 12 de 2009). [Ley 1357 de 2009]. Por la cual se modifica el Código Penal. Diario Oficial: 47.531.

Colombia. Congreso de la República (junio 24 de 2011). [Ley 1453 de 2011]. Por medio de la cual se reforma el Código Penal, el Código de Procedimiento Penal, el Código de Infancia y Adolescencia, las reglas sobre extinción de 
dominio y se dictan otras disposiciones en materia de seguridad. Diario Oficial: 48.110.

Colombia. Consejo Nacional de Política Económica y Social [CONPES]. (2013). CONPES 3793: Política Nacional Anti Lavado de Activos y Contra la Financiación del Terrorismo - ALA/CFT. Bogotá: Departamento Nacional de Planeación DNP - Consejo Nacional de Política Económica y Social.

Colombia. Constitución Política de Colombia (1991).

Colombia. Corte Constitucional (8 de noviembre de 2007). Sentencia C-931 [Magistrado Ponente: Marco Gerardo Monroy Cabra]. Expediente: LAT-287.

Colombia. Corte Constitucional (2 de abril de 2009). Sentencia C-254 [Magistrado Ponente: Nilson Pinilla Pinilla]. Expediente: RE-145.

Colombia. Corte Suprema de Justicia, Sala de Casación Penal. (11 de abril de 2007) Sentencia-Proceso 23.593 [Magistrado Ponente: Sigifredo Espinosa Pérez]

Colombia. Corte Suprema de Justicia, Sala de Casación Penal. (9 de abril de 2008) Sentencia-Proceso 23.754 [Magistrado Ponente: Sigifredo Espinosa Pérez]

Colombia. Corte Suprema de Justicia, Sala de Casación Penal. (5 de agosto de 2009) Sentencia-Proceso 28.300 [Magistrado Ponente: Sigifredo Espinosa Pérez] 
Colombia. Corte Suprema de Justicia, Sala de Casación Penal. (2 de abril de 2011) Sentencia-Proceso 27.144 [Magistrado Ponente: Jorge Luis Quintero Milanés]

Colombia. Corte Suprema de Justicia, Sala de Casación Penal. (9 de abril de 2014) Sentencia-Proceso 42.722 [Magistrado Ponente: Patricia Salazar]

Colombia. Ministerio de Justicia (octubre 4 de 1991). [Decreto 2266 de 1991]. Por el cual se adoptan como legislación permanente unas disposiciones expedidas en ejercicio de las facultades del Estado de Sitio. Diario Oficial: 40.078 .

Colombia. Presidencia de la República (agosto 18 de 1989). [Decreto 1856 de 1989]. Por el cual se toman medidas encaminadas al restablecimiento del orden público. Diario Oficial: 38.945.

Colombia. Presidencia de la República (agosto 24 de 1989). [Decreto 1895 de 1989]. Por el cual se dicta medidas tendientes al restablecimiento del orden público. Diario Oficial: 38.951.

Colombia. Presidencia de la República (abril 2 de 1993). [Decreto 663 de 1993]. Por medio del cual se actualiza el Estatuto Orgánico del Sistema Financiero y se modifica su titulación y numeración. Diario Oficial: 40.820 .

Colombia. Presidencia de la República (noviembre 17 de 2008). [Decreto 4333 de 2008]. Por el cual se declara el Estado de Emergencia Social. Diario Oficial: 47.176 . 
Colombia. Superintendencia Bancaria (1996). Circular Básica Jurídica (Circular Externa 007/96). Bogotá: Superintendencia Bancaria.

Cusgüen, E. (2005). El derecho tributario en la investigación penal: referido al lavado de activos y al enriquecimiento ilícito de particulares. Bogotá: Leyer.

Durrieu, R. (2011). El bien jurídico protegido en el Delito de Lavado de Dinero. Anuario de Doctrina del Colegio de Abogados de la Ciudad de Buenos Aires.

Goite, M \& Medina, A. (2015). El delito de lavado de activos: necesario análisis desde una dimensión. En: Armienta, G.; Goite, M.; Medina, A.; Gambino, L. \& García, L. (coordinadores). El lavado de dinero en el siglo XXI: una visión desde los instrumentos jurídicos internacionales la doctrina y las leyes en América Latina y España. México: Universidad Autónoma de Sinaloa; Unijuris.

Gómez, J. (2003). Teoría del delito. Bogotá: Ediciones Doctrina y Ley.

González, C. (2005). ¿Hacia dónde va el mercado de remesas en Colombia? En: Organización Internacional para las Migraciones. Memorias del Seminario. Migración Internacional, el Impacto y las Tendencias de las Remesas en Colombia. Bogotá: Panamericana.

Grupo de Acción Financiera de Sudamérica [GAFISUD] (2012). Estándares internacionales sobre la lucha contra el lavado de activos y el financiamiento del terrorismo y la proliferación: las Recomendaciones del GAFI. 
Gutiérrez, H. (2013). Colombia: Overview of corruption and anti-corruption. Bergen: U4 Anti-Corruption Resource Centre.

Hernández, H. A. (2009). Aspectos fundamentales del delito de lavado de activos: una visión desde la legislación colombiana y la guatemalteca. Justicia Juris $6(11), 65-80$.

Hernández, H. A. (2014). Lavado de activos: características generales y su tipificación penal en Colombia. En: Muñoz, M. A. (et., al.). Apuntes de Derecho Penal Económico. Bogotá: Pontificia Universidad Javeriana, Facultad de Ciencias Jurídicas; Grupo Editorial Ibáñez.

Iturralde, M.; Ariza, L. (2011). El tratamiento penal del narcotráfico y delitos conexos. En: Gaviria, A.; Mejía, D. (compiladores). Políticas antidroga en Colombia: éxitos, fracasos y extravíos. Bogotá: Universidad de los Andes.

Ley 599 de 2000. Por la cual se expide el Código Penal. Diario Oficial No. 44.097, 24 de julio de 2000 .

Martínez, W.; Pardo, P. \& Vera, O. (2014). Estudio de sentencias sobre lavado de activos proferidas entre los años 2005 y 2013. En: Martínez, W. (editor académico). Síntesis y reflexiones sobre el sistema antilavado de activos y contra la financiación del terrorismo en Colombia. Universidad del Rosario; Unidad de Información y Análisis Financiero - UIAF. 
Oficina de las Naciones Unidas contra la Droga y el Delito UNODC (2011). Riesgo de Lavado de Activos en Instrumentos Financieros y Comerciales. Bogotá: Programa de Asistencia Legal para América Latina y el Caribe.

Palma, J. (2000). Los delitos de blanqueo de capitales. Madrid: Edersa.

Salazar, S. (2007). La acción de extinción frente al lavado de activos. En: Rodríguez, A; Martínez, W y Sintura, F. Estudios de Derecho Penal Económico. Bogotá: Universidad del Rosario, Facultad de Jurisprudencia.

Salvo, N. (2014). Modelos de imputación penal a personas jurídicas: estudio comparado de los sistemas español y chileno. Tesis doctoral: Universidad Autónoma de Barcelona.

Sánchez, L. E. (2002). Lavado de dinero: delito transnacional. Buenos Aires: La Ley.

Sandoval, J. (2003). Causales de ausencia de responsabilidad penal. Revista de Derecho, (19), 1-18

Suárez, L \& Hurtado, Á. (2014). La dimensión económica del lavado de activos. Bogotá: UIAF.

Superintendencia Bancaria de Colombia (1998). Lavado de activos: una actividad multifacética. Bogotá: Superintendencia Bancaria de Colombia. 
Thoumi, F.E (2012). "Colombian Organized Crime: From Drug Trafficking to parastatal Bands and Widespread Corruption", Studies of Organized Crime, 11: 131-148.

Unidad de Información y Análisis Financiero [UIAF] (2013). Compilación de tipologías de lavado de activos y financiación del terrorismo 2004-2013. Bogotá: UIAF.

Unidad de Información y Análisis Financiero [UIAF]; Superintendencia de Notariado y Registro (2013). Guía para la Prevención del Riesgo de Lavado de Activos y Financiación del Terrorismo en el Sector Notariado. Bogotá: UIAF Superintendencia de Notariado y Registro. 